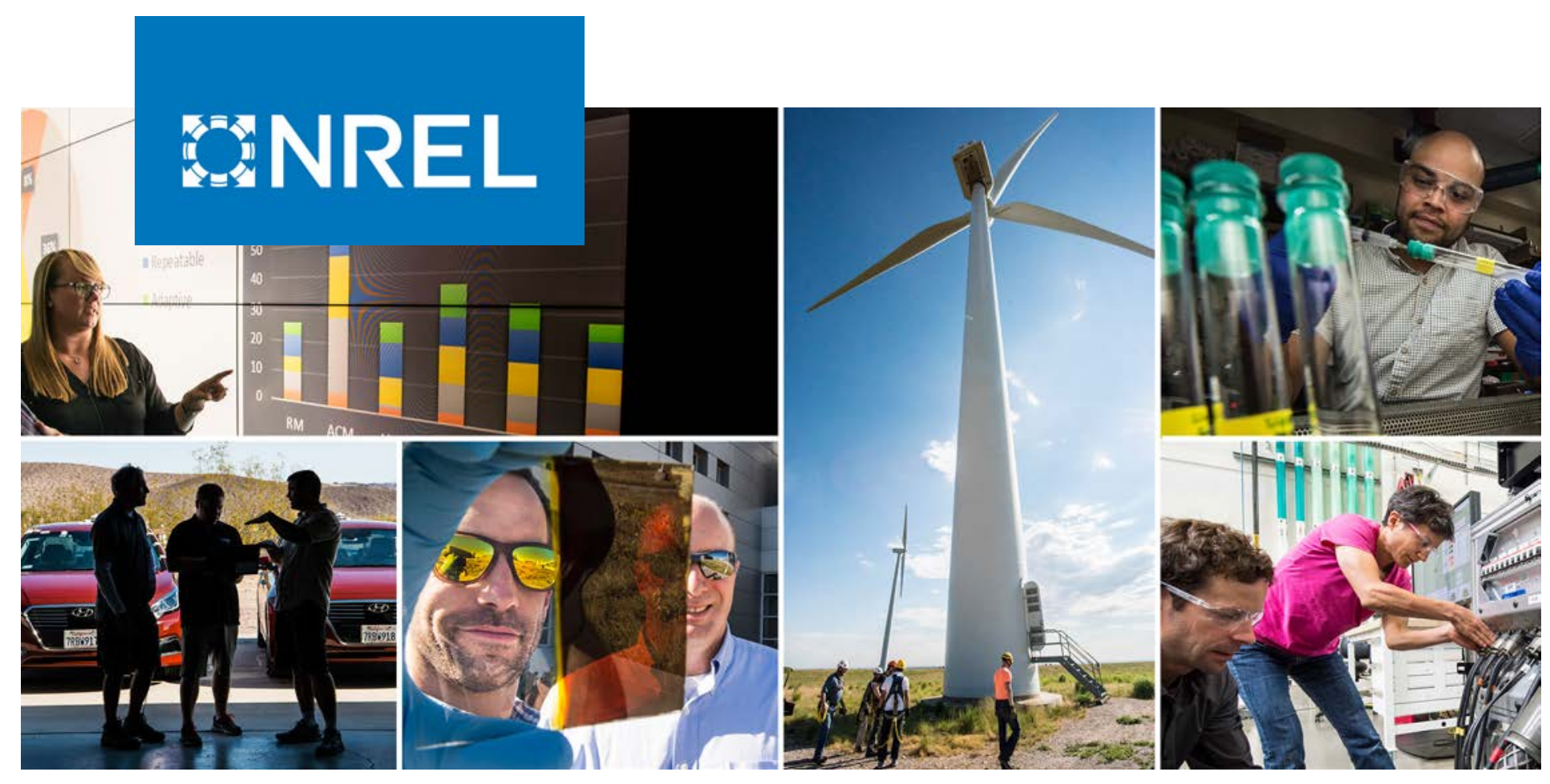

\title{
Cross-Border Energy Trade between Nepal and India: Trends in Supply and Demand
}

David J. Hurlbut

National Renewable Energy Laboratory

NREL is a national laboratory of the U.S. Department of Energy Office of Energy Efficiency \& Renewable Energy

Operated by the Alliance for Sustainable Energy, LLC

This report is available at no cost from the National Renewable Energy Laboratory (NREL) at www.nrel.gov/publications.

\section{Technical Report}

NREL/TP-6A20-72345

April 2019 


\section{GNREL}

\section{Cross-Border Energy Trade between Nepal and India: Trends in Supply and Demand}

David J. Hurlbut

National Renewable Energy Laboratory

Prepared under State Department Agreement No. IAG-16-02007

\section{Suggested Citation}

Hurlbut, David J.. 2019. Cross-Border Energy Trade between Nepal and India:

Trends in Supply and Demand. Golden, CO: National Renewable Energy Laboratory.

NREL/TP-6A20-72345. https://www.nrel.gov/docs/fy19osti/72345.pdf.

NREL is a national laboratory of the U.S. Department of Energy Office of Energy Efficiency \& Renewable Energy Operated by the Alliance for Sustainable Energy, LLC

This report is available at no cost from the National Renewable Energy Laboratory (NREL) at www.nrel.gov/publications.

Contract No. DE-AC36-08GO28308
Technical Report NREL/TP-6A20-72345 April 2019

National Renewable Energy Laboratory 15013 Denver West Parkway Golden, CO 80401 303-275-3000 • www.nrel.gov 


\section{NOTICE}

This work was authored by the National Renewable Energy Laboratory, operated by Alliance for Sustainable Energy, LLC, for the U.S. Department of Energy (DOE) under Contract No. DE-AC36-08GO28308. Funding provided by U.S. Department of State. The views expressed herein do not necessarily represent the views of the DOE or the U.S. Government.

This report is available at no cost from the National Renewable Energy Laboratory (NREL) at www.nrel.gov/publications.

U.S. Department of Energy (DOE) reports produced after 1991 and a growing number of pre-1991 documents are available free via www.OSTI.gov.

Cover Photos by Dennis Schroeder: (clockwise, left to right) NREL 51934, NREL 45897, NREL 42160, NREL 45891, NREL 48097, NREL 46526.

NREL prints on paper that contains recycled content. 


\section{Preface}

This paper is part of a series of studies on the opportunities for - and associated value of increased power trade in the South Asian region, including India, Nepal, Bhutan, Bangladesh, and Sri Lanka. This work is supported by the U.S. Department of State's Bureau of South and Central Asian Affairs Regional Connectivity Program.

Another study in this series uses production cost modeling to quantify potential cross-border energy trading benefits more thoroughly, based on scenarios derived from the economic analysis in this study. The third study uses the economic and production cost analyses to explore regulatory issues that could affect cross-border electricity trade. The results reflect input from power system engineers, planners, regulators, and electricity developers as part of stakeholder engagement under the U.S. Agency for International Development's South Asia Regional Initiative for Energy Integration. 


\section{Acknowledgments}

The author is grateful for operational data, advice, and comment from the Nepal Electricity Authority, especially from Kulman Ghising, Rabindra Raj Shrestha, Shaligram Acharya, Hitendra Dev Shakya, Bishnu Prasad Shrestha, and Binod Lohani. U.S. Embassy staffparticularly Kevin Price - also provided invaluable logistical assistance during in-country visits to Nepal, as did Michael Boyd and Shanker Khagi from the U.S. Agency for International Development's Nepal Mission.

Troy Kofroth of the Millennium Challenge Corporation and S.K. Soonee of the Power System Operation Corporation of India provided important feedback on initial drafts of this report. Nate Blair, Jaquelin Cochran, Jeff Logan, Brendan McBennett, David Palchak, and Amy Rose of the National Renewable Energy Laboratory (NREL) provided important detailed review comments. Donna Heimiller of NREL provided geographic information systems support. 


\section{List of Acronyms}

CBA

CBET

GIS

IEX

IPP

LMP

PCM

PPA

NEA

NREL

RLDC

RoR

VOLL

WECS cost-benefit analysis

cross-border energy trading

geographic information systems

Indian Energy Exchange

independent power producer

locational marginal price

production cost modeling

power purchase agreement

Nepal Electricity Authority

National Renewable Energy Laboratory

Regional Load Dispatch Center

run-of-river

value of lost load

Water and Energy Commission Secretariat 


\section{Executive Summary}

This report examines the economic factors affecting cross-border energy trading (CBET) between Nepal and India. Its objective is to identify market factors and institutional issues that are most likely to affect the usefulness of infrastructure investments aimed at maximizing the benefits of CBET. The analysis assesses supply and demand characteristics by examining hourly load data, pricing data, generation capacity, tariffs, and historical CBET flows. It uses Government of Nepal load forecasts, planned capacity additions, and historical trends for construction delays to project plausible trajectories of shortages and surpluses in domestic generation.

A 2017 study for the South Asian Regional Initiative for Energy Integration concluded that Nepal, which generates nearly all of its domestic power from hydroelectric resources, could reap significant economic benefits by expanding CBET with India (SARI/EI and IRADe 2017). Strategic transmission expansion could affect how much of these latent benefits are actually achieved, however. In turn, the effectiveness of different transmission expansion options could depend on domestic economic conditions and how they might change over time.

Figure ES 1 shows the key interconnection points between the two countries' grids. Supply and demand on both sides of the Indo-Nepalese border will affect which points have the greatest potential for maximizing CBET benefits. The aim of this economic analysis is to understand trends in supply, demand, and prices, and to identify which transmission corridors have the best potential for benefiting both countries.

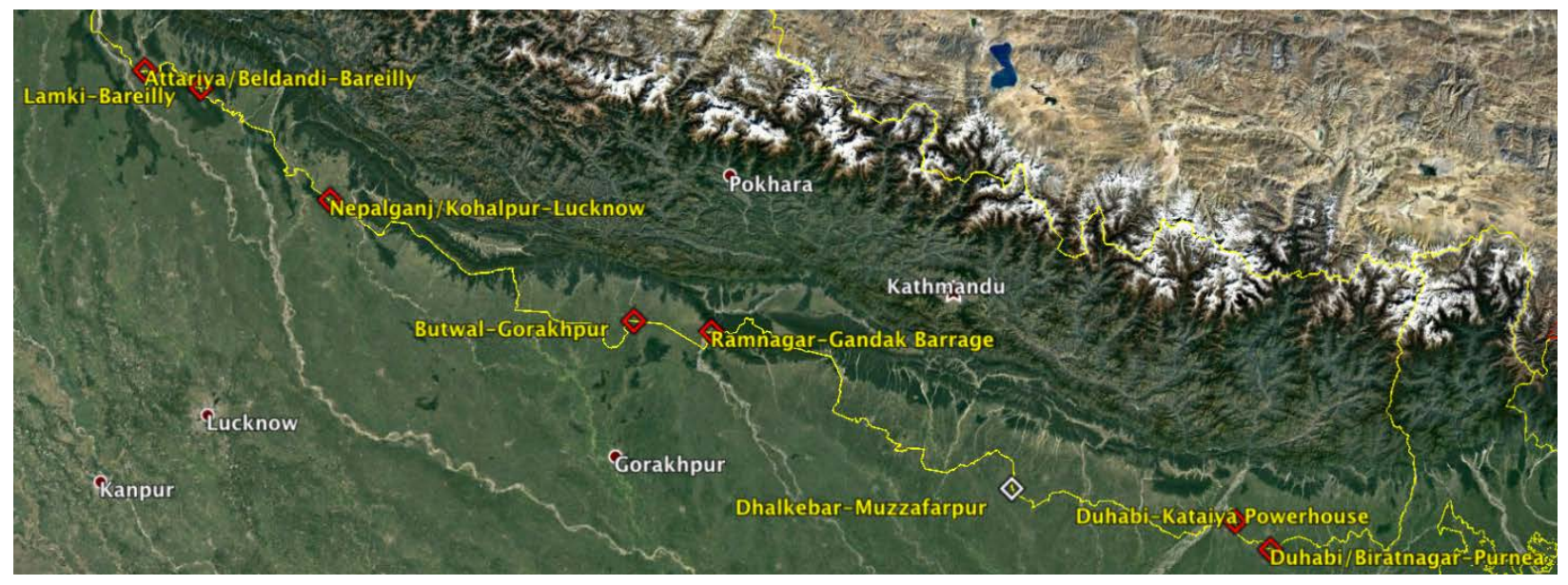

Figure ES 1. Major CBET interconnections between Nepal and India.

Note: The Dhalkebar-Muzzafarpur connection would repower the existing line from 132 kilovolts (kV) to $400 \mathrm{kV}$, requiring no additional right-of-way.

The economic analysis supports four major conclusions:

- Up to 2018 the primary driver for CBET has been the alleviation of load shedding in Nepal, but the completion of new generation will most likely reduce load shedding and Nepal's need to import power from India for that purpose. Future CBET in both directions will likely depend on the cost of alternative generation sources in each country. 
- Market fundamentals and longer-term trends appear to favor connections to India's Northern Regional Load Dispatch Center (RLDC) region, which tends to be a net importer of electricity. Upgrading the Butwal-Gorakhpur path is consistent with this likely value proposition.

- While connections across the Western Tarai area could further increase mutually beneficial CBET opportunities, doing so could depend on system upgrades within Nepal to increase the capacity to move power west of the Butwal flowgate.

- Maximizing the value of any new transmission intended to enhance CBET value will likely depend on bilateral tariff reform and greater operational coordination between Nepal and India.

The results of this economic analysis help characterize regional grid scenarios for 2022 that are simulated with production cost modeling, which is the focus of the companion paper in this series, "Cross-Border Energy Trade between Nepal and India: Assessment of Trading Opportunities" (McBennett et al. 2019). These technical simulations provide additional detail on the regional distribution of benefits. 


\section{Table of Contents}

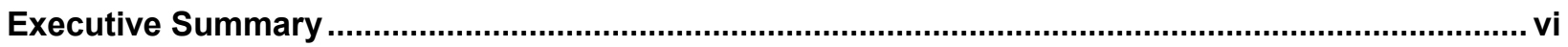

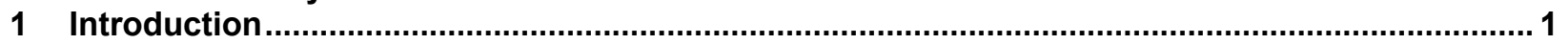

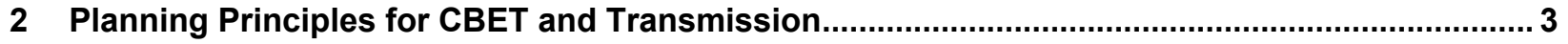

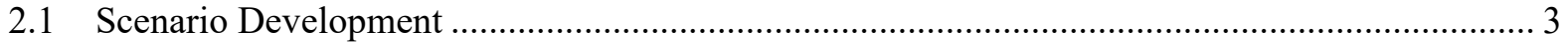

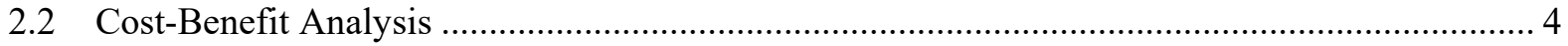

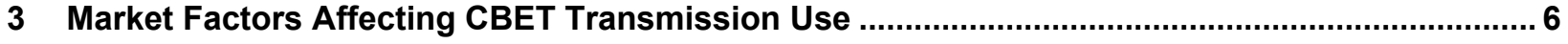

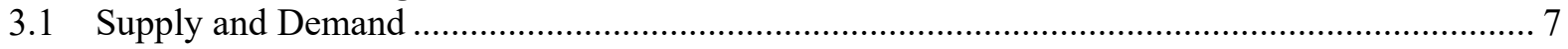

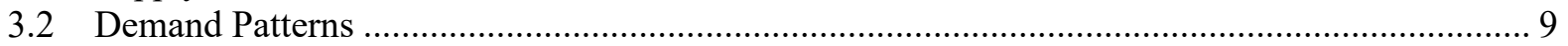

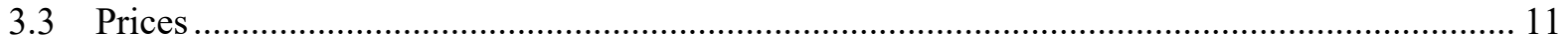

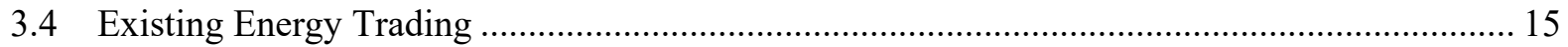

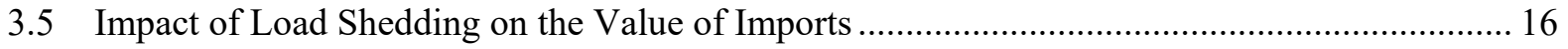

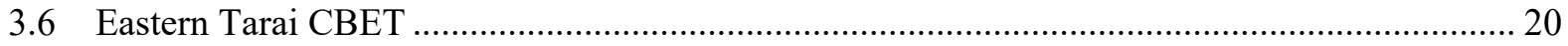

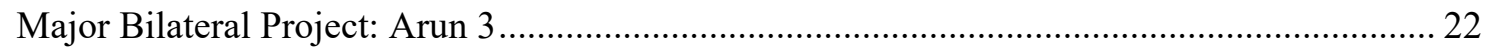

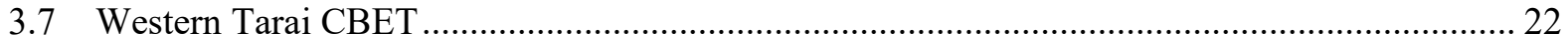

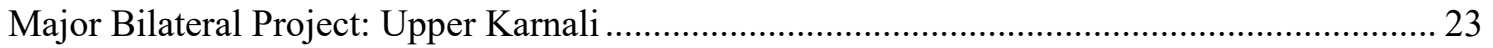

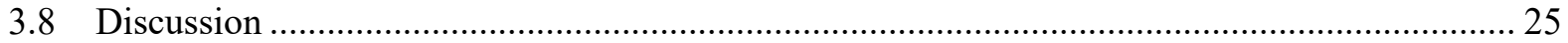

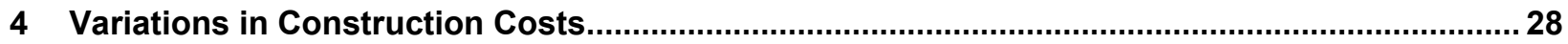

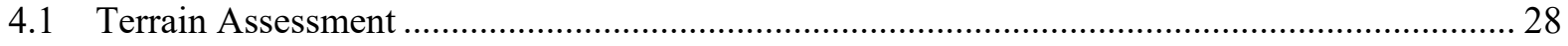

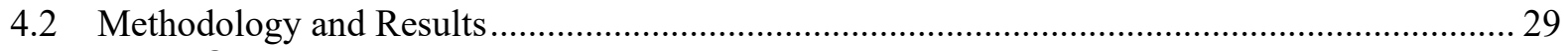

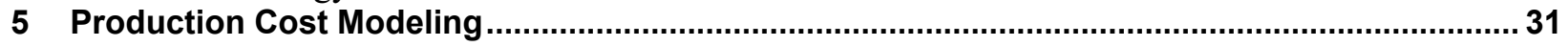

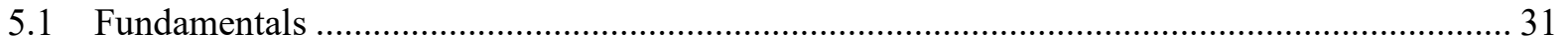

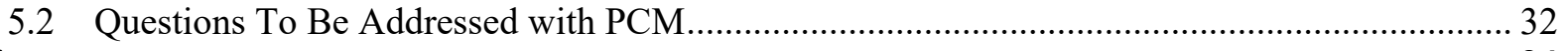

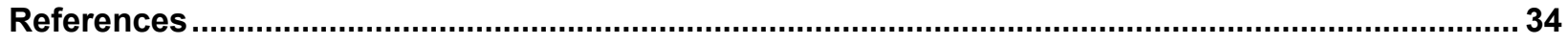

Appendix: Exchange Rates Applied to the Analysis ................................................................... 36 


\section{List of Figures}

Figure ES 1. Major CBET interconnections between Nepal and India ................................................... vi

Figure 1. Geographic alignment of significant grid regions in Nepal and India...................................... 6

Figure 2. Distribution of 2016-2017 electricity sales in Nepal by region and customer type.................... 8

Figure 3. One-year time series of daily peak generation delivered to load in Nepal ................................ 10

Figure 4. Three-year time series of daily peak and minimum load in India. .......................................... 10

Figure 5. Monthly IEX prices and power flows across the Eastern Tarai CBET ................................... 12

Figure 6. Monthly power flows across Western Tarai CBET ............................................................... 12

Figure 7. Price duration curves for Uttar Pradesh and Bihar .............................................................. 13

Figure 8. Same-hour price differences between Uttar Pradesh and Bihar ............................................. 13

Figure 9. Monthly generation for Nepal, by resource type ................................................................. 17

Figure 10. Short-term projection of supply and served load for test hour .............................................. 18

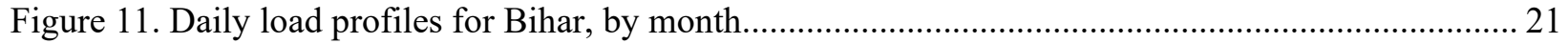

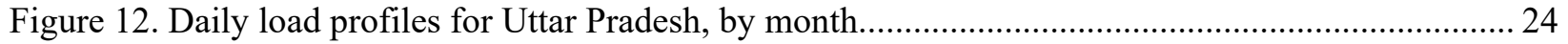

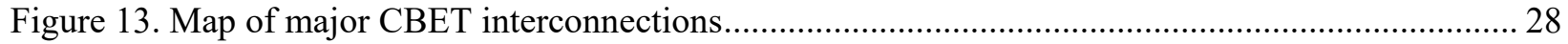

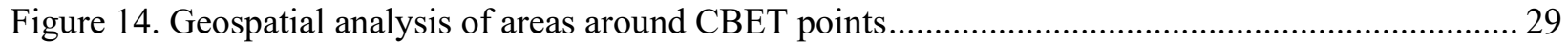

\section{List of Tables}

Table 1. Daily Profiles of Nepal's Electricity Generation, by Nepali Calendar Month............................ 7

Table 2. India's Northern and Eastern Load Dispatch Center Regions, Year Ending April 2017 ............... 9

Table 3. Prices Paid by NEA for Energy from New Merchant Generators .............................................. 11

Table 4. Market Prices for Day-Ahead Exchanges in Bihar and Uttar Pradesh, by Month....................... 14

Table 5. Distribution of Nepal's Electricity Imports, by Month ............................................................ 15

Table 6. Domestic Generation Available for Critical Load Shedding Hours in Nepal............................. 18

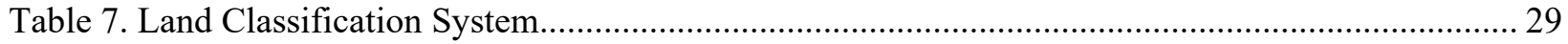

Table 8. Scoring of CBET Points Based on Geospatial Attributes.......................................................... 30 


\section{Introduction}

Electricity demand on both sides of the border between Nepal and India is growing rapidly, increasing the urgency of infrastructure planning and development. This report draws on international experience to develop a framework for transmission planning specifically aimed at prioritizing opportunities for increasing cross-border energy trading (CBET) along the IndoNepalese border.

The severe earthquake and aftershocks that devastated the Kathmandu Valley and central Nepal in mid-2015 complicate any time series analysis of electricity demand and production in the country. For this reason, this report focuses generally on the Nepalese calendar year beginning April 13, 2016 (1 Baishakh 2073) as the start of the country's post-earthquake redevelopment period. ${ }^{1}$ This time frame allows at least one full reporting year of operational data from the Nepal Electricity Authority (NEA). The preceding year was dominated by extraordinary economic disruption and one-time emergency response, so much as to reduce confidence in including observations for that year in an analysis of future economic trends.

Moreover, Nepal's constitutional and political framework in the post-earthquake period is substantially different from what it was before the disaster. This could affect Indo-Nepalese CBET in two important ways relevant to this report. First, Nepal's infrastructure planning could follow a strategy that is significantly different from pre-2015 planning. A change in strategy could affect investment in new large-scale hydropower projects, as well as national strategies for dealing with domestic issues such as dry-season load shedding and the course of post-earthquake economic growth. Second, in many cases Indo-Nepalese CBET currently adheres to pre-2015 bilateral arrangements that are unconnected to power market economics. One important question that the governments of Nepal and India might consider is whether to replace or amend these pre-2015 agreements with institutions that are more market-oriented. Much of the analysis contained in this report assumes that CBET can adapt to changing market conditions.

Efficiently implemented CBET expands the electric system's operational footprint. Numerous studies - as well as experience in several countries - demonstrate the value of greater integration over a larger geography. The benefits include lower cost of scheduling and dispatch, reduced area control error, a greater selection of resources for balancing, greater operational flexibility, and lower cost of renewable energy integration. For example, the introduction of a regional, multi-jurisdiction market for settling energy imbalances has saved utilities in the western United States more than $\$ 400$ million (Indian rupees 2,850 crore) since it began in 2014. That market includes one large system operator that accounts for about $60 \%$ of the group's total demand, and five smaller control areas. Of the $\$ 71$ million (Indian rupees 458 crore) in benefits seen in the second quarter of 2018, more than $61 \%$ accrued to the smaller control areas (CAISO 2018).

CBET is not an exercise separate from all other transmission planning. On both sides of the border, electricity planning addresses larger objectives and requires comprehensive power system planning. CBET might add to the range of options for achieving economically efficient

\footnotetext{
${ }^{1}$ The Indian civil calendar year and the Nepali year do not completely align but are reasonably close enough for aggregating data. For the Gregorian calendar year 2016, the month Vaishakha on India's calendar began six days after 1 Baishakha on the Nepali calendar.
} 
electricity service to all, but it is not a goal by itself. What makes CBET a special category of system planning is the need for collaboration and joint planning across national boundaries. Joint planning ensures that assumptions about CBET and what it can accomplish are consistent. This enhances the quality of each country's own planning and can expand options for achieving domestic goals.

This report begins with an overview of multi-jurisdictional transmission planning in other world power markets. Rather than provide an exhaustive literature review, the aim is to distill best practices to a select number of key principles that can guide joint planning by India and Nepal. Among the most important of these principles is the need to create transparency by involving key stakeholders.

The report then examines the most important market factors that will influence the value of CBET at different points along the border. The report concludes with a summary of the specific questions arising from the economic analysis that production cost modeling can help address. This economic analysis informs the scenarios modeled in the companion study, "Cross-Border Energy Trade between Nepal and India: Assessment of Trading Opportunities" (McBennett et al. 2019).

The modeling results, along with the economic analysis in this report, will provide the basis for an examination of regulatory, planning, and operational changes that might improve opportunities for CBET. 


\section{Planning Principles for CBET and Transmission}

Multi-jurisdiction regional transmission operators around the world rely on formal, transparent planning processes to prioritize investments in new transmission infrastructure. ${ }^{2}$ These processes are tailored to the needs of each particular market, but many have common aims, such as:

- Minimizing total electric system costs

- Meeting all reliability standards

- Supporting government policies in the most economically efficient manner

- Allocating the cost of transmission investments in a way that matches the distribution of benefits.

Systematic planning is even more important when the grid spans multiple jurisdictions, each with its own decision-making authority. A transparent planning process allows all participants to evaluate a wide variety of options, test theoretical benefits against practical limitations, and identify strategies that benefit everyone. In many jurisdictions, planning is done over a moving 5-, 10- or 20-year time horizon, updated every 1 or 2 years. This allows for full consideration of known plant retirements, the online dates of plants currently under construction, and load growth.

In planning transmission for CBET between India and Nepal, this study draws on two tools: scenario development and cost-benefit analysis (CBA). This section provides a basic explanation of both tools. The economic analysis in Section 3 will help define scenarios around which transmission analysis can be framed. The production cost modeling (PCM) described in Section 3.8 and the construction factors modeled in Section 4 will provide CBA inputs.

\subsection{Scenario Development}

Scenario analysis is a planning exercise that anticipates long-term structural changes to the economy at large. It is particularly useful for countries anticipating major economic transitions. Scenarios could include significantly greater use of electric vehicles, changes in energy imports or exports, and shifts in personal consumption patterns, as well as adoption of policies aimed at

${ }^{2}$ For example, the U.S.-based Midcontinent Independent System Operator uses the following principles in its multiyear transmission expansion planning:

- Make the benefits of an economically efficient electricity market available to customers by identifying transmission projects that provide access to electricity at the lowest total electric system cost.

- Develop a transmission plan that meets all applicable [government and] transmission owner planning criteria and safeguards local and regional reliability through identification of transmission projects to meet those needs.

- Support state and federal energy policy requirements by planning for access to a changing resource mix.

- Provide an appropriate cost allocation mechanism that ensures that costs of transmission projects are allocated in a manner roughly commensurate with the projected benefits of those projects.

- Analyze system scenarios and make the results available to state and federal energy policy makers and other stakeholders to provide context and to inform choices.

- Coordinate planning processes with neighbors and work to eliminate barriers to reliable and efficient operations. 
increasing CBET. Potential scenarios that could be particularly relevant to cross-border transmission projects for India and Nepal might include:

- Institutional reform. Replacing administrative rules with markets can affect the size of economic benefits as well as how those benefits are distributed. Reform scenarios can range from modest changes such as bilateral spot markets to major changes such as the creation of an independent system operator and security-constrained economic dispatch.

- Rural electrification. The pace and geographic characteristics of grid-connected rural electrification can affect both the quantity of electricity needed and the points of congestion on the transmission system.

- Industrialization and accelerated economic growth. Economic development that accelerates industrial and commercial electricity consumption can affect the system's ability to use demand response as a tool for maintaining reliability and reducing peak load. This is especially important if either country has renewable energy goals.

- Plant retirements and additions. Replacing old thermal plants can change the total cost of generation and - depending on the size of the plants - congestion on the transmission system.

The number of potential scenarios that could be modeled is large. Therefore, the goal of Section 3 is to narrow the list of useful scenarios to focus on factors that could have a large economic impact across the region based on conditions that can be observed and measured using data that are currently available for this project. Future analyses can examine scenarios that are not tested here.

Sensitivity analyses test the robustness of conclusions to changes in external variables such as fuel prices and load growth. Sensitivities that span a range of plausible future conditions enable identification of "no regrets" solutions: investments that provide additional value to society regardless of how key factors might change.

\subsection{Cost-Benefit Analysis}

Transmission planners typically use CBA to compare the net economic effect of build-out proposals. CBA compares the cost of a new transmission project with its predicted economic benefits, summarized as a cost-benefit ratio:

$$
\text { cost-benefit ratio }=\frac{\sum_{\mathrm{i}} \text { benefits }_{\mathrm{i}}}{\text { transmission project costs }}
$$

where $i$ is a specific type of economic change attributable to the new line, such as lower systemwide variable cost of generation, increase or decrease in the amount of operating reserves needed, or a change in the expected amount of unserved energy. The components may be estimated over the economic life of the investment on a net present value basis or may be levelized to annual values. ${ }^{3}$

\footnotetext{
${ }^{3}$ A net present value approach allows for costs or benefits to vary from one year to another.
} 
The denominator includes only the direct cost of building the transmission project. Any other non-project cost is included in the numerator as a "benefit" with a negative value. For example, a new transmission line to a wind power development zone could reduce total production costs (a positive benefit) but might also increase the amount and cost of operating reserves needed to ensure reliability (a negative benefit). The numerator would account for both; the cost-benefit ratio would compare the aggregation of all benefits - positive and negative - against the project's direct cost.

A cost-benefit ratio greater than 1.0 indicates that the estimated benefits of a transmission project are greater than its cost. Regulatory authorities may set decision benchmarks to guide transmission planning. In the United States, for example, some authorities give greater weight to a proposed transmission project if the cost-benefit ratio is larger than 1.25 (FERC 2011). 


\section{Market Factors Affecting CBET Transmission Use}

Future market conditions will ultimately govern whether any new transmission line is used and useful. This section describes market conditions observed through NEA operational data, factors likely to affect forward trends, and how these trends might affect the prioritization of CBET transmission expansion options.

The Indo-Nepalese border touches four distinct power markets. As the map in Figure 1 illustrates, these four areas align somewhat geographically into two potential CBET areas:

- The Western Tarai, comprising power flows between western Nepal and India's Northern Regional Load Dispatch Center (RLDC) region

- The Eastern Tarai, comprising power flows between the rest of Nepal and India's Eastern RLDC region.

Internal east-west flows are limited on both sides of the border. This suggests that each northsouth CBET path could have its own economic dynamics, making it reasonable to treat them separately. Differences include energy pricing patterns, seasonal demand, and the value of economically driven trades in both directions. These in turn could affect the value of new transmission across each CBET area.

Butwal is a pivotal point on Nepal's power grid. A 132-kV substation constitutes the sole flowgate to the country's western system. What makes Butwal especially strategic for CBET is its ability to connect to Uttar Pradesh and India's Northern RLDC region via Gorakhpur. Both countries have identified a future $400-\mathrm{kV}$ line between Butwal and Gorakhpur as a bilateral priority (GoI/GoN 2017).

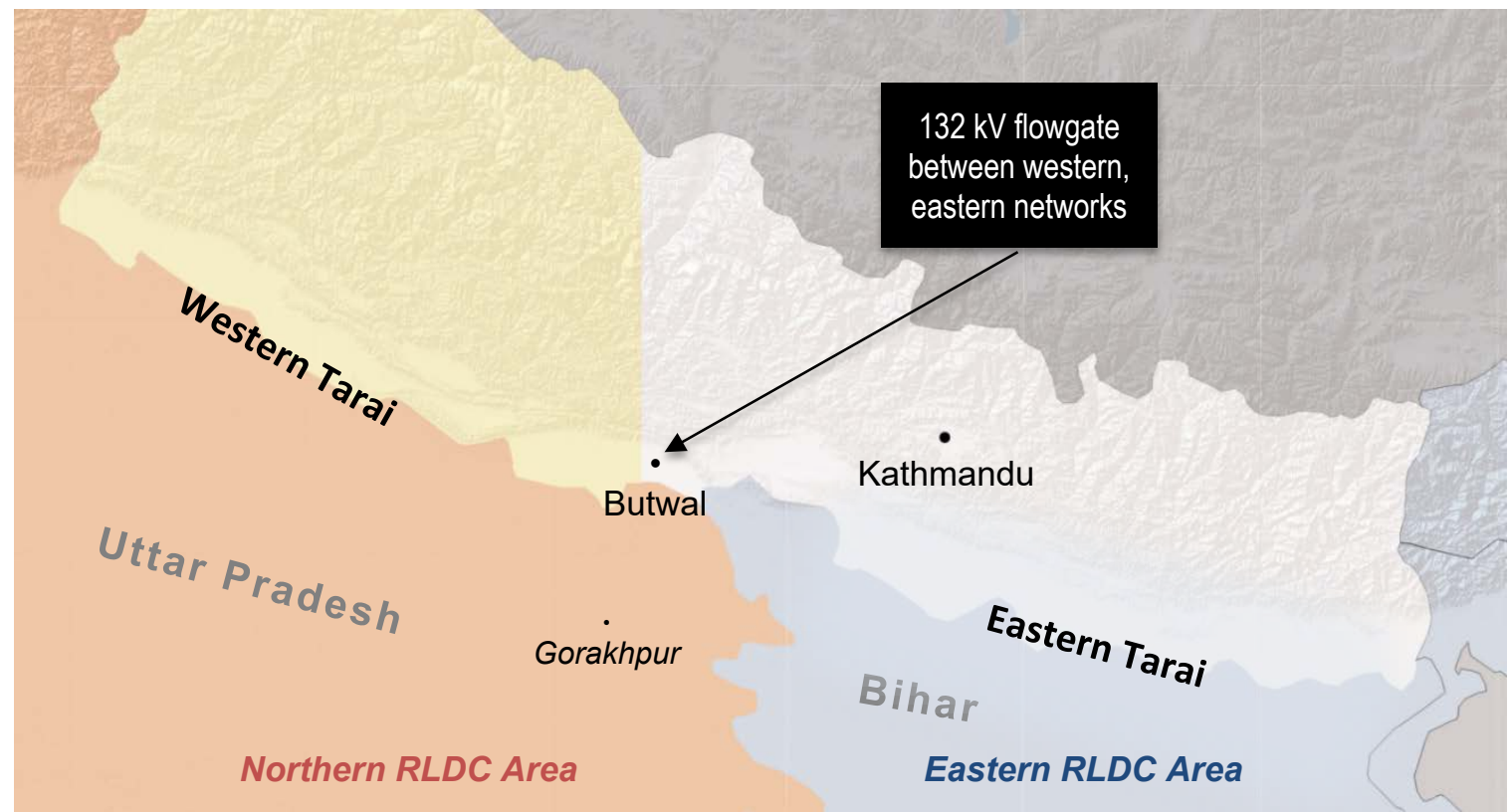

Figure 1. Geographic alignment of significant grid regions in Nepal and India 


\subsection{Supply and Demand}

NEA had 526 megawatts (MW) of generating capacity in 2017, 90\% of which was hydropower (NEA 2017a). Less than 1\% of NEA's capacity is located west of Butwal. ${ }^{4}$ Independent power producers (IPPs) had about $441 \mathrm{MW}$ of capacity, with only $32 \mathrm{MW}$ operating west of Butwal. Developers currently have nearly 2 gigawatts $(\mathrm{GW})$ of new capacity financed and under construction, with $5 \%$ of that total west of Butwal (NEA 2017c).

Due to its high reliance on run-of-river (RoR) hydropower, Nepal's domestic generation resources produce the most power during the post-monsoon months from Bhadra to Kartik (late August to early November). Table 1 shows the temporal distribution of Nepal's domestic generation for 2016-2017, averaged by hour for each month.

Figure 2 shows the geographic distribution of power sales in Nepal for the 12 months ending April 12, 2017. The Western Tarai (points west of Butwal) constitutes about 10\% of NEA sales, while the Butwal area itself accounts for about 14\% (NEA 2017a).

Table 1. Daily Profiles of Nepal's Electricity Generation by Nepali Calendar Month

(April 13, 2016 through April 12, 2017, averaged by month)

\begin{tabular}{|c|c|c|c|c|c|c|c|c|c|c|c|c|}
\hline & 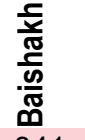 & 荵 & 突 & 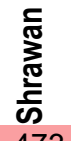 & $\begin{array}{l}\frac{\pi}{2} \\
\frac{\pi}{\pi} \\
\frac{\pi}{m}\end{array}$ & $\frac{\sqrt{\frac{c}{3}}}{\frac{c}{\infty}}$ & 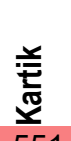 & 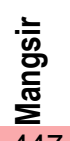 & 똥 & $\sum_{272}^{\overline{5}}$ & $\frac{5}{5}$ & $\begin{array}{l}\frac{\pi}{2} \\
\frac{\vec{t}}{\pi} \\
\frac{\pi}{U}\end{array}$ \\
\hline 24 & 341 & 357 & 462 & 473 & 536 & 553 & 551 & 447 & 325 & 273 & 304 & 320 \\
\hline 23 & 355 & 366 & 470 & 477 & 530 & 558 & 557 & 463 & 347 & 307 & 321 & 342 \\
\hline 22 & 338 & 365 & 494 & 500 & 555 & 565 & 571 & 498 & 396 & 367 & 367 & 372 \\
\hline 21 & 340 & 365 & 478 & 490 & 554 & 572 & 588 & 534 & 453 & 422 & 422 & 421 \\
\hline 20 & 326 & 358 & 464 & 478 & 555 & 576 & 597 & 550 & 483 & 446 & 454 & 470 \\
\hline 19 & 321 & 341 & 456 & 472 & 555 & 574 & 600 & 575 & 522 & 493 & 501 & 499 \\
\hline 18 & 281 & 329 & 458 & 467 & 550 & 573 & 606 & 598 & 540 & 445 & 470 & 371 \\
\hline 17 & 296 & 336 & 451 & 462 & 551 & 562 & 582 & 517 & 414 & 336 & 380 & 356 \\
\hline 16 & 322 & 346 & 450 & 464 & 543 & 561 & 574 & 532 & 421 & 352 & 389 & 372 \\
\hline 15 & 324 & 348 & 442 & 456 & 532 & 557 & 563 & 526 & 428 & 347 & 399 & 380 \\
\hline 14 & 287 & 346 & 445 & 449 & 533 & 552 & 553 & 527 & 428 & 349 & 397 & 386 \\
\hline 13 & 285 & 343 & 447 & 459 & 543 & 557 & 565 & 526 & 432 & 351 & 399 & 382 \\
\hline 12 & 288 & 341 & 446 & 463 & 539 & 558 & 571 & 528 & 439 & 372 & 414 & 408 \\
\hline 11 & 287 & 339 & 451 & 472 & 541 & 556 & 578 & 540 & 462 & 399 & 431 & 423 \\
\hline 10 & 284 & 340 & 448 & 474 & 551 & 570 & 585 & 552 & 474 & 407 & 443 & 416 \\
\hline 9 & 263 & 341 & 453 & 480 & 547 & 569 & 587 & 554 & 486 & 415 & 455 & 410 \\
\hline 8 & 237 & 334 & 451 & 480 & 551 & 574 & 591 & 561 & 503 & 439 & 470 & 427 \\
\hline 7 & 251 & 332 & 453 & 478 & 552 & 569 & 598 & 565 & 487 & 410 & 452 & 406 \\
\hline 6 & 278 & 337 & 451 & 475 & 543 & 571 & 594 & 539 & 420 & 344 & 392 & 359 \\
\hline 5 & 277 & 332 & 454 & 467 & 550 & 558 & 573 & 478 & 349 & 289 & 329 & 327 \\
\hline 4 & 284 & 334 & 454 & 463 & 545 & 553 & 553 & 442 & 318 & 265 & 300 & 302 \\
\hline 3 & 300 & 337 & 452 & 467 & 543 & 549 & 547 & 432 & 308 & 259 & 292 & 300 \\
\hline 2 & 308 & 337 & 455 & 463 & 542 & 553 & 547 & 432 & 310 & 261 & 295 & 309 \\
\hline 1 & 321 & 350 & 464 & 470 & 538 & 552 & 552 & 442 & 312 & 264 & 293 & 303 \\
\hline
\end{tabular}

Source: NEA 2017b

\footnotetext{
${ }^{4}$ This excludes about $4.5 \mathrm{MW}$ of isolated hydro capacity.
} 


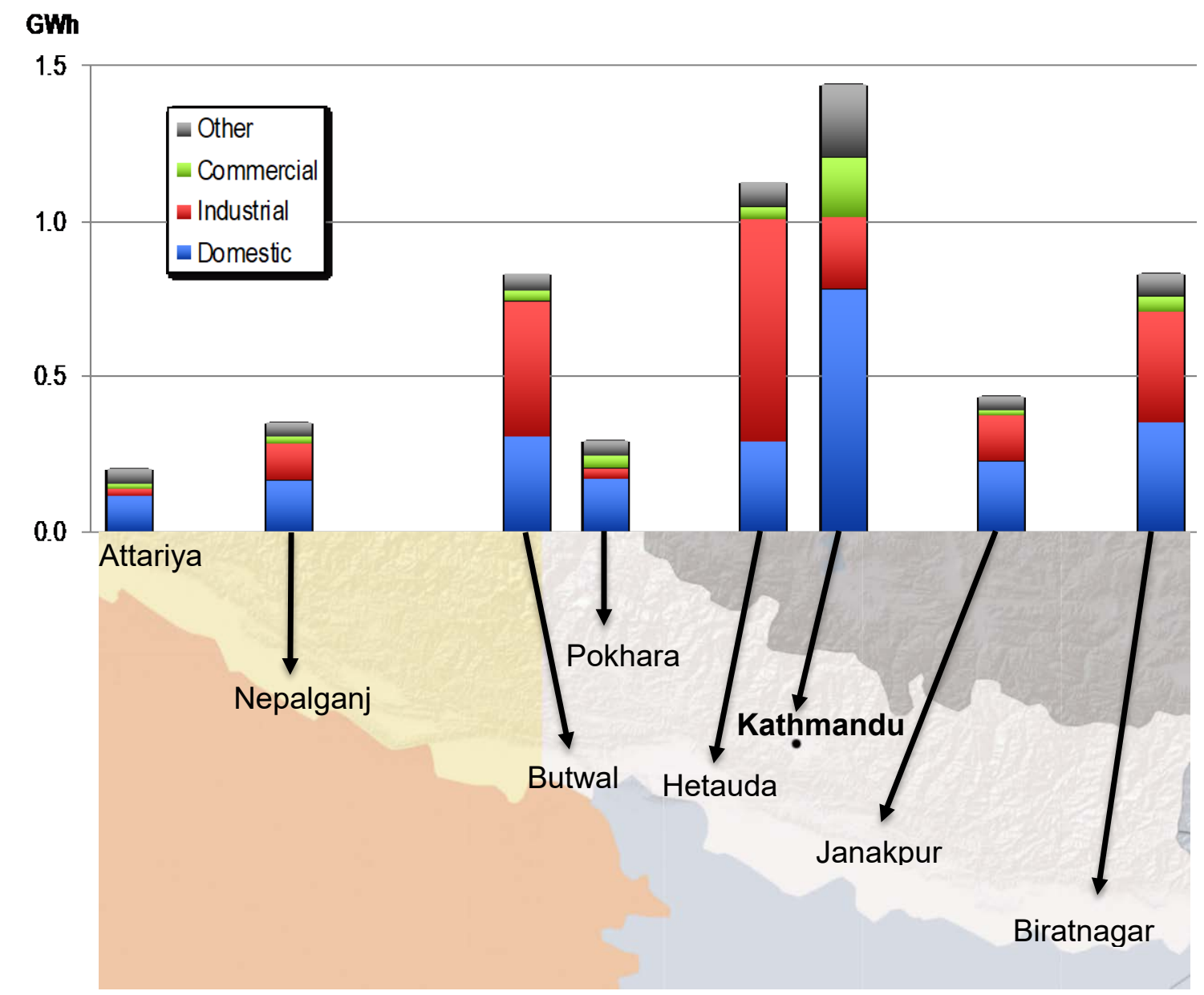

Figure 2. Distribution of 2017-2018 electricity sales in Nepal by region and customer type.

Source: NEA 2018.

Note: $\mathrm{GWh}=$ gigawatt hour.

Domestic demand has been slightly higher than industrial demand for the past 10 years (NEA 2017a and 2018). For the year ending April 2018, 43\% of NEA's sales were to domestic customers and $38 \%$ were to industrial customers. Nearly $73 \%$ of Nepal's industrial demand is concentrated near Hetauda, Butwal, and Biratnagar. This geographic distribution has implications for load interruption. In other world markets, industrial consumers are major participants in strategies such as interruptible tariffs and demand response. Therefore, loadshedding strategies that focus on industrial load would tend to have a larger impact on the Eastern Tarai CBET area.

The geographic division in India is defined by grid operations. India's national power grid includes two dispatch center regions that are adjacent to Nepal. Uttar Pradesh, bordering western Nepal, is the state with the largest load in the Northern RLDC region. The Eastern RLDC region borders Nepal through the state of Bihar. 
Table 2. India's Northern and Eastern Load Dispatch Center Regions, Year Ending April 2017

\begin{tabular}{lcc}
\hline & Northern RLDC & Eastern RLDC \\
\hline Effective capacity (2017) & $\begin{array}{c}75.1 \mathrm{GW} \\
\text { (36\% hydro, other renewables) }\end{array}$ & $\begin{array}{c}37.1 \mathrm{GW} \\
(16 \% \text { hydro })\end{array}$ \\
\hline Annual energy met (2016-2017) & $345.4 \mathrm{TWh}$ & $134.1 \mathrm{TWh}$ \\
Net energy flow between regions & \multicolumn{2}{c}{$\begin{array}{c}\text { 20.1 TWh } \leftarrow \\
\text { (to Northern RLDC } \\
\text { from Eastern } R L D C)\end{array}$} \\
\hline
\end{tabular}

Source: POSOCO 2017a and 2017b, CEA 2016a and 2016b.

Note: "Effective capacity" is the total installed capacity by technology adjusted by the most recent applicable all-India forced outage rates reported by India's Central Electricity Authority. TWh = terawatt hour.

Table 2 contrasts supply and demand for the two RLDC regions. The Northern region has twice as much generating capacity but more than two and a half times the energy demand. Net exports from the Eastern region to the Northern region were equivalent to $15 \%$ of the total energy met in the Eastern region for the year ending March 2017. These patterns indicate that India is not a homogeneous market with respect to future CBET. Based on 2017 conditions, India's Northern regional network connecting to the Western Tarai appears to have a relatively stronger appetite for imports that is fairly consistent throughout the year. The Eastern regional network connecting to the Eastern Tarai has been an exporter historically, but this could change as India adds more renewable resources in Rajasthan and elsewhere. ${ }^{5}$

\subsection{Demand Patterns}

Daily and seasonal load patterns can affect the direction, quantity, and value of cross-border exchanges. Patterns may be complementary (higher demand on one side of the border coinciding with surplus supply on the other side), or they may be parallel and result in more intense competition for scarce resources at particular times.

Figure 3 and Figure 4 suggest load patterns on the Nepali and Indian sides of the Eastern Tarai CBET area are somewhat similar. Daily peak demand tends to occur shortly after sunset, both in Bihar and Nepal. The coincidence of peak demand could result in competition for cross-border supplies that would tend to be strongest in the early evening. If this pushes wholesale market prices higher, the direction and volume of CBET would depend on the cost of each side's domestic supply alternatives that are on the economic margin in the early evening hours. For example, if greater competition causes on-peak power prices across the Eastern Tarai to increase to $\$ 50 /$ megawatt hour (MWh), the economic benefit of cross-border exchanges to India would depend on whether adding more of India's own domestic resources would cost it more than $\$ 50 / \mathrm{MWh}$.

\footnotetext{
${ }^{5}$ The additional wind and solar capacity allows the Northern RLDC region to replace its imports from the Eastern region with generation from states such as Rajasthan that have abundant wind and solar resources. These scenarios are modeled in McBennett et al. 2019.
} 


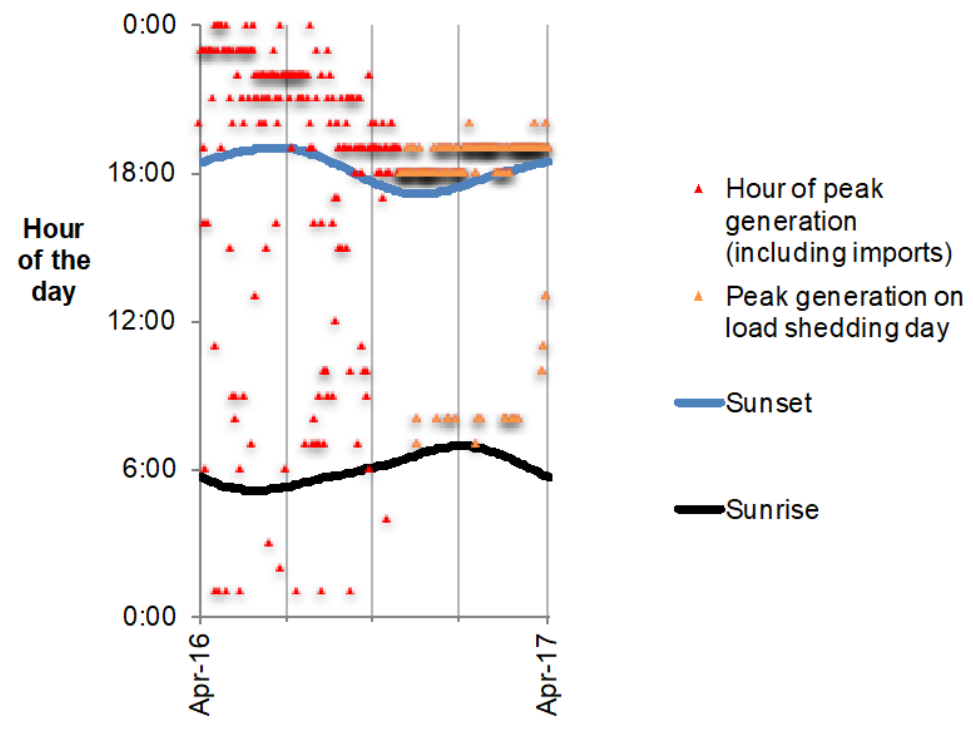

Figure 3. One-year time series of daily peak generation delivered to load in Nepal.

Source: NEA 2017b.

Note: Chart does not quantify load shedding. Orange markers indicate the time of peak demand during load shedding, but not the amount of demand.

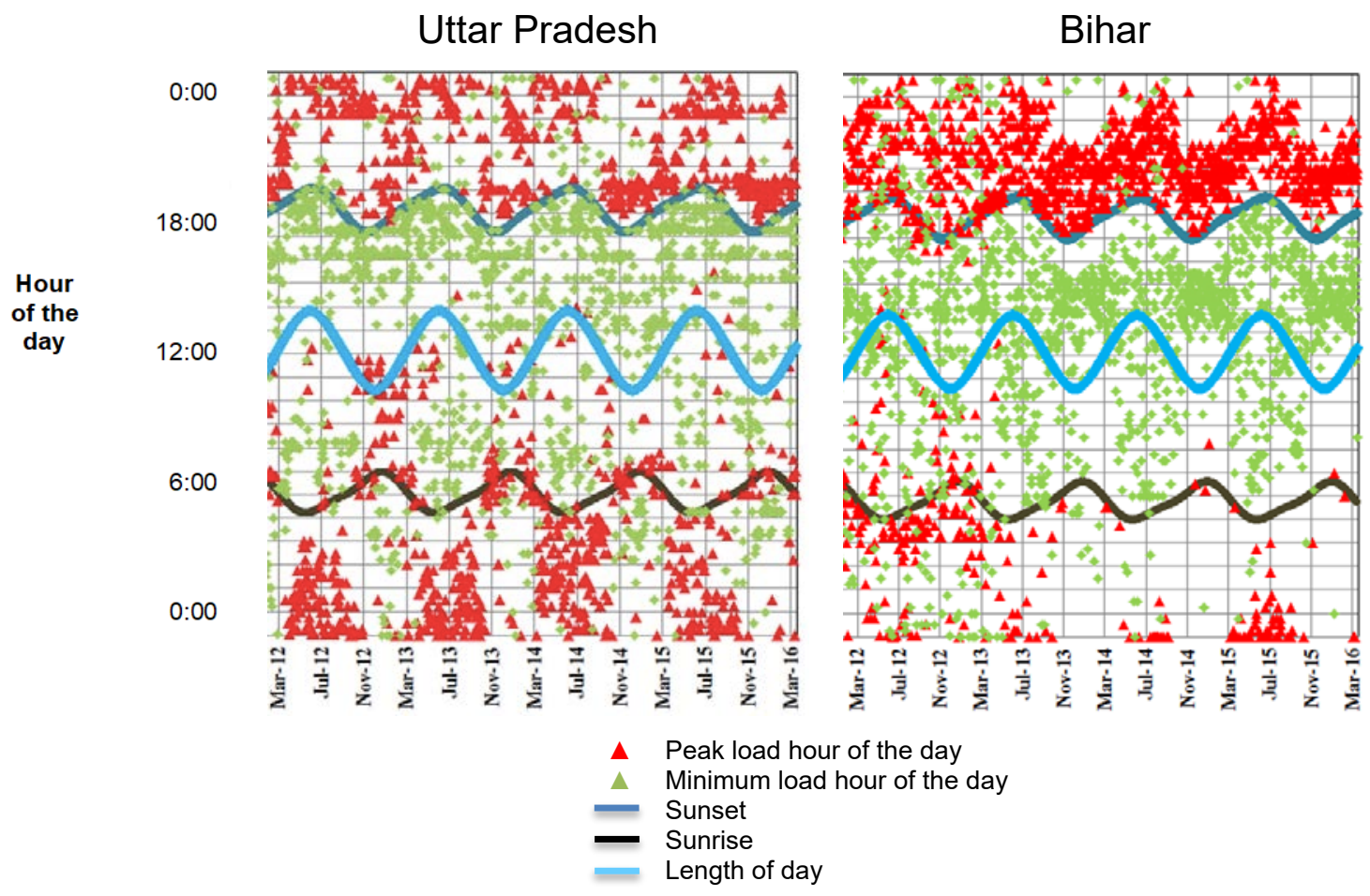

Figure 4. Three-year time series of daily peak and minimum load in India.

Source: POSOCO 2017a and 2017b. 
Peak-hour trends in Uttar Pradesh are more distributed, which tends to make the state's demand for imports more consistent throughout the day. On the other side of the Western Tarai, demand in Nepal is about $0.1 \%$ of demand in the Northern RLDC region and too small to provide any significant economic counterbalance. This suggests that the economic success of new large-scale generation in western Nepal might follow market conditions in India more than those in Nepal.

\subsection{Prices}

NEA pays domestic power producers more for energy delivered during the dry season than for energy delivered during the rainy season, with an additional premium based on energy delivered during peak load hours (NEA 2017d).

RoR generators generally receive $\$ 81.75$ per MWh for energy delivered during the dry season and $\$ 46.72$ for energy delivered during the rest of the year. Peaking RoR generators can receive as much as $\$ 102.68$ per MWh if they deliver at their rated capacity four to six hours during the peak period of the day. Table 3 shows the tariff schedule for NEA payments to merchant generators.

The domestic payment rates influence CBET because they set the economic benchmark for future power exports to India. For example, if market prices in Bihar during the dry season are less than \$46.72, IPPs will export little or no energy from Nepal if they can sell to NEA.

Table 3. Prices Paid by NEA for Energy from New Merchant Generators

\begin{tabular}{r|ll}
\hline \multicolumn{2}{c}{ Dry Season } & Wet Season \\
\hline Peaking run-of-river hydro & & \\
4-6 hours at peak & $\$ 102.68 / \mathrm{MWh}$ & \\
3-4 hours at peak & $\$ 91.48 / \mathrm{MWh}$ & \$46.72/MWh \\
2-3 hours at peak & $\$ 85.64 / \mathrm{MWh}$ & (all run-of-river types, \\
1-2 hours at peak & $\$ 82.73 / \mathrm{MWh}$ & all hours) \\
Simple run-of-river hydro & $\$ 81.75 / \mathrm{MWh}$ & \\
\hline
\end{tabular}

Source: NEA 2017d.

Note: Rates escalate $3 \%$ per year for 8 years.

Most of the energy currently imported into Nepal across the Eastern Tarai is under a power purchase agreement (PPA) with NTPC Vidyut Vyapar Nigam, which manages cross-border activity for India's government-owned NTPC Ltd. ${ }^{6}$ The PPA rate is about \$56/MWh (NEA 2017a). Energy imported into Nepal across the Tanakpur-Mahendranagar line is under a PPA with PTC India Ltd. at a rate of about \$53/MWh (NEA 2017a).

${ }^{6}$ The Government of India holds a $75 \%$ interest in NTPC. 


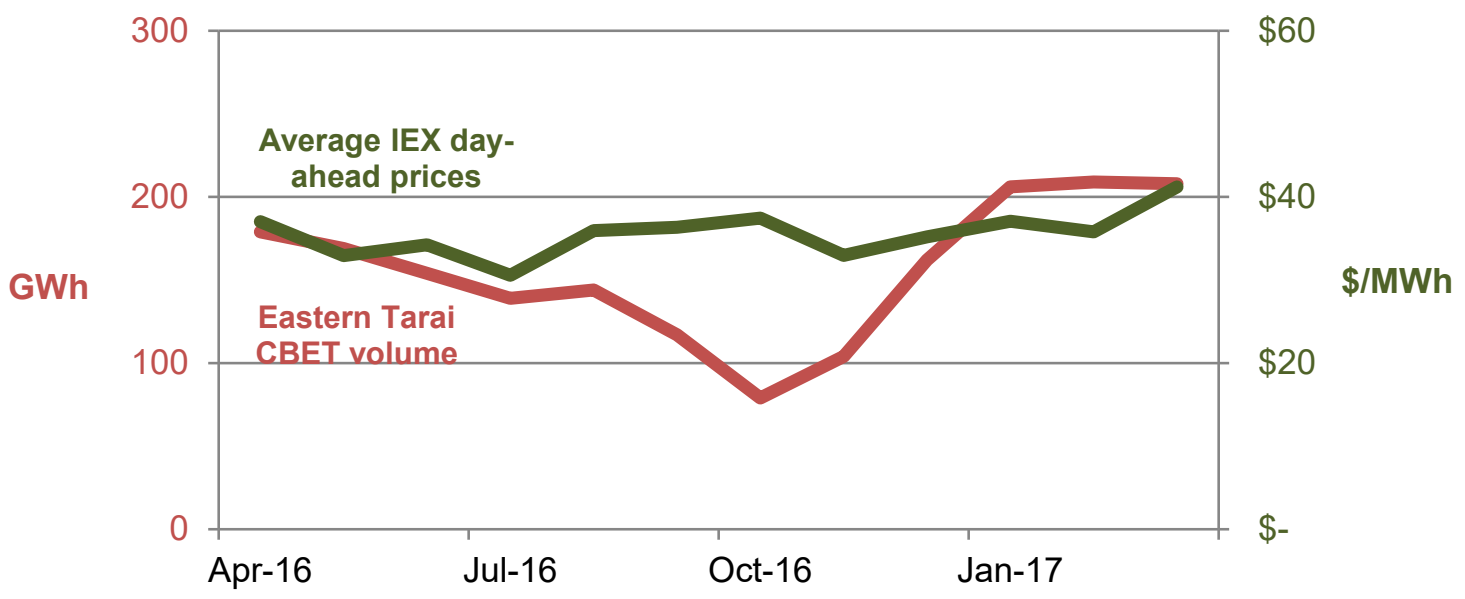

Figure 5. Monthly IEX prices and power flows across the Eastern Tarai CBET. Source: IEX 2017, POSOCO 2017a.

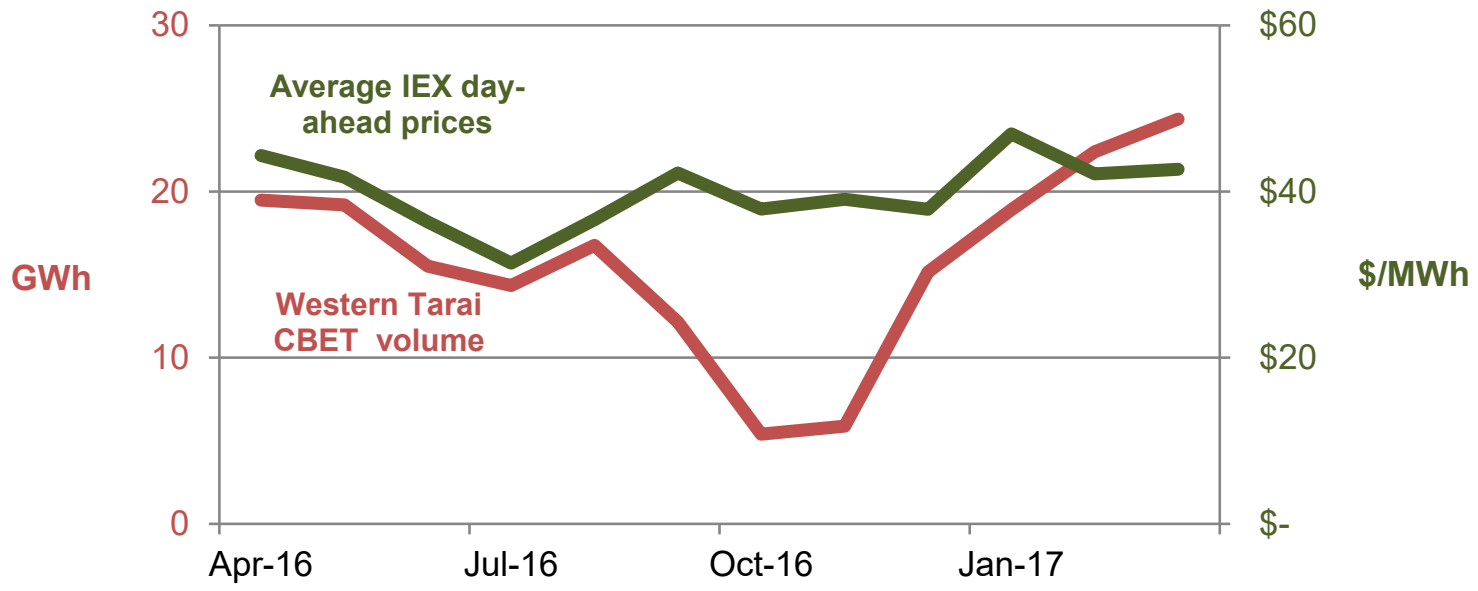

Figure 6. Monthly power flows across Western Tarai CBET.

Source: IEX 2017, POSOCO 2017b.

Within India, prices for energy traded on the Indian Energy Exchange (IEX) vary based on supply and demand by location. For example, day-ahead prices in Bihar averaged $\$ 36 / \mathrm{MWh}$ for the 12 months ending April 12, 2017, about 36\% lower than the PPA price governing most exchanges across the Eastern Tarai. ${ }^{7}$ Figure 5 tracks the volume of power traded across the CBET area (left axis) against average monthly price on the IEX for Bihar (right axis).

By comparison, IEX prices for Uttar Pradesh averaged \$40/MWh for the year ending April 12, 2017. Figure 6 shows that the highest market prices generally occurred in January, with mid-day prices ( 9 a.m. -5 p.m.) averaging at or above $\$ 50 / \mathrm{MWh}$ for December through February. Thus, the official PPA rate currently governing exchanges across the Western Tarai CBET region was

\footnotetext{
${ }^{7}$ IEX places Odisha in a pricing zone separate from the rest of the Eastern RLDC region. Data reported here are for the northern part of the region, excluding Odisha.
} 
sometimes near or below market prices, unlike the rate for exchanges across the Eastern Tarai CBET region, which was almost always above market prices.

Wholesale market energy prices can run higher in Uttar Pradesh than in Bihar. This is economically consistent with the fact that the Northern RLDC region was a net importer and the Eastern RLDC region a net exporter during this time. Figure 7 shows the one-year price duration curves for the two states. (Note that matching x-axis points on the two curves do not correspond to the same hour.)

Figure 8 shows the difference in prices between Uttar Pradesh and Bihar for the same market hours, arranged as a duration curve. Day-ahead prices were the same $64 \%$ of the time. About $30 \%$ of the time, prices in Uttar Pradesh were higher by as much as \$25/MWh (IEX 2017). Hourly price differences tended to be distributed throughout the operating day.

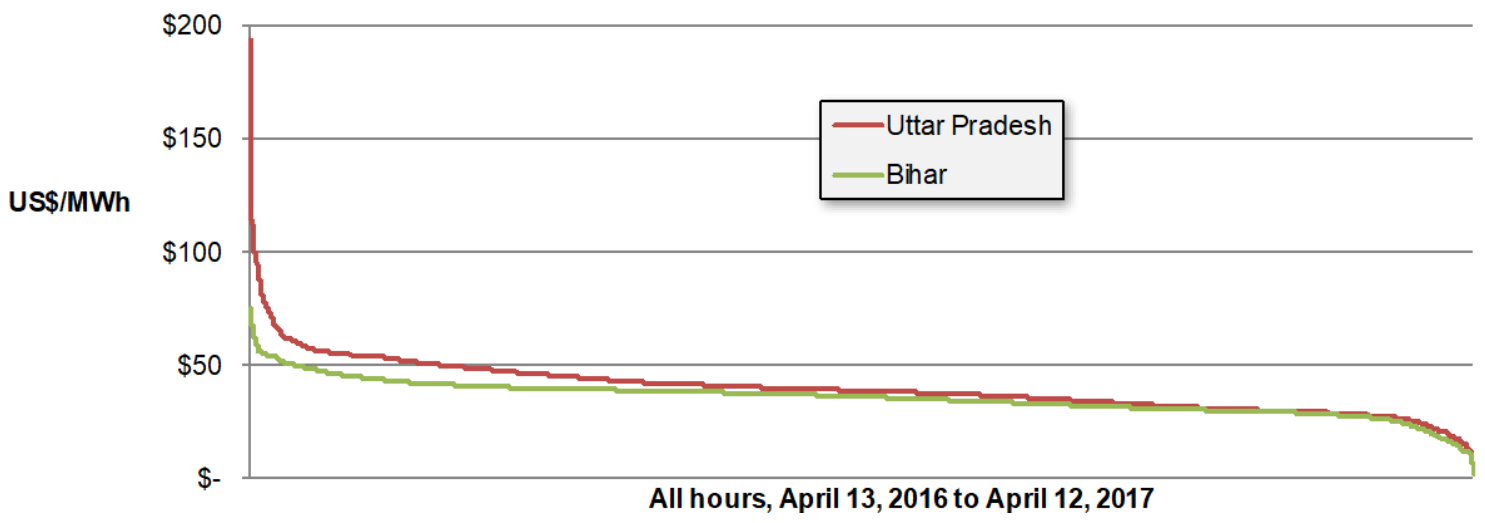

Figure 7. Price duration curves for Uttar Pradesh and Bihar.

Source: IEX 2017. Note: Curves are not time-synchronized.

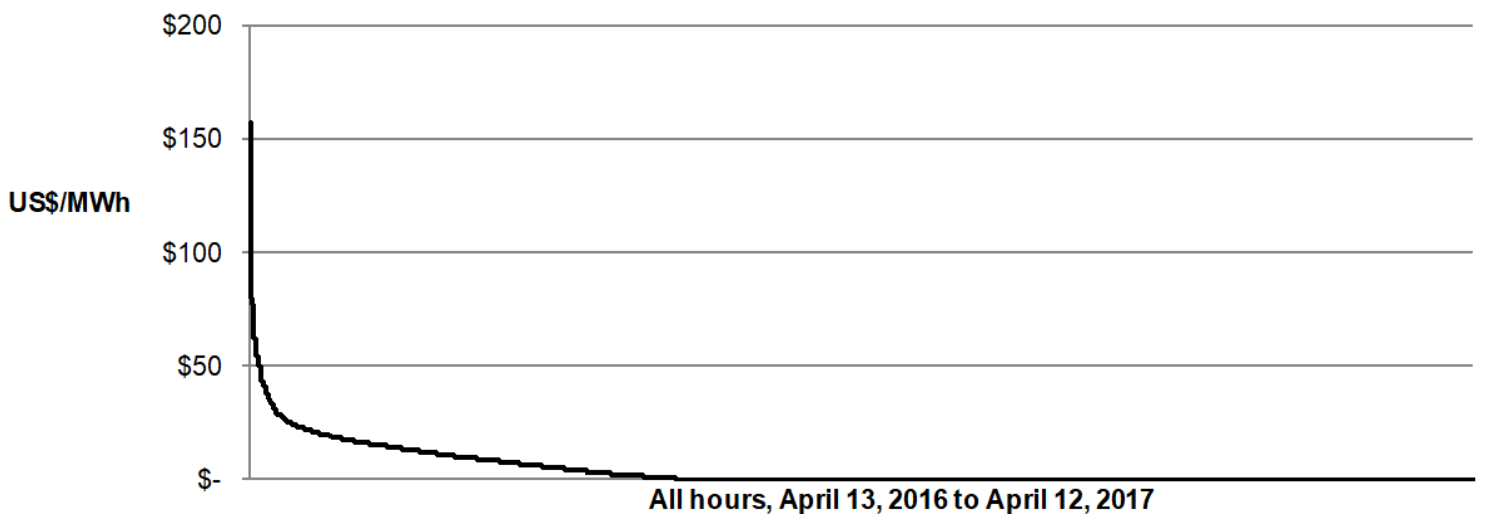

Figure 8. Same-hour price differences between Uttar Pradesh and Bihar

Source: IEX 2017. Note: At no time were day-ahead prices in Bihar higher than in Uttar Pradesh. 
Table 4. Market Prices for Day-Ahead Exchanges in Bihar and Uttar Pradesh, by Month

(April 13, 2016, through April 12, 2017, averaged by month)

\begin{tabular}{|c|c|c|c|c|c|c|c|c|c|c|c|c|}
\hline & 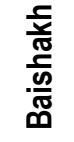 & 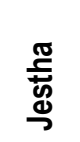 & $\begin{array}{l}\text { 동 } \\
\text { \$ } \\
\text { 定 }\end{array}$ & 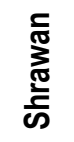 & 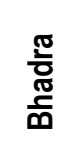 & $\frac{\text { 高 }}{\frac{1}{3}}$ & $\begin{array}{l}\text { 意 } \\
\underline{\underline{T}}\end{array}$ & 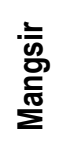 & 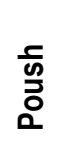 & 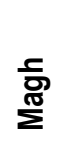 & $\frac{5}{\frac{5}{\sqrt{0}}}$ & 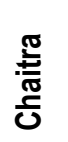 \\
\hline & \multicolumn{12}{|c|}{ Bihar (\$/MWh) } \\
\hline 24 & $\$ 44$ & $\$ 36$ & $\$ 35$ & $\$ 31$ & $\$ 38$ & $\$ 38$ & $\$ 35$ & $\$ 28$ & $\$ 28$ & $\$ 31$ & $\$ 32$ & $\$ 41$ \\
\hline 23 & $\$ 46$ & $\$ 39$ & $\$ 38$ & $\$ 35$ & $\$ 43$ & $\$ 39$ & $\$ 38$ & $\$ 29$ & $\$ 31$ & $\$ 31$ & $\$ 32$ & $\$ 43$ \\
\hline 22 & $\$ 46$ & $\$ 40$ & $\$ 40$ & $\$ 42$ & $\$ 50$ & $\$ 45$ & $\$ 42$ & $\$ 34$ & $\$ 35$ & $\$ 34$ & $\$ 38$ & $\$ 49$ \\
\hline 21 & $\$ 42$ & $\$ 40$ & $\$ 41$ & $\$ 47$ & $\$ 53$ & $\$ 47$ & $\$ 44$ & $\$ 38$ & $\$ 39$ & $\$ 38$ & $\$ 39$ & $\$ 50$ \\
\hline 20 & $\$ 39$ & $\$ 38$ & $\$ 39$ & $\$ 41$ & $\$ 51$ & $\$ 46$ & $\$ 44$ & $\$ 38$ & $\$ 41$ & $\$ 40$ & $\$ 40$ & $\$ 50$ \\
\hline 19 & $\$ 34$ & $\$ 32$ & $\$ 35$ & $\$ 31$ & $\$ 37$ & $\$ 39$ & $\$ 45$ & $\$ 41$ & $\$ 44$ & $\$ 41$ & $\$ 38$ & $\$ 41$ \\
\hline 18 & $\$ 35$ & $\$ 33$ & $\$ 34$ & $\$ 27$ & $\$ 33$ & $\$ 36$ & $\$ 43$ & $\$ 45$ & $\$ 46$ & $\$ 43$ & $\$ 35$ & $\$ 38$ \\
\hline 17 & $\$ 37$ & $\$ 38$ & $\$ 36$ & $\$ 28$ & $\$ 33$ & $\$ 36$ & $\$ 38$ & $\$ 38$ & $\$ 40$ & $\$ 40$ & $\$ 38$ & $\$ 40$ \\
\hline 16 & $\$ 39$ & $\$ 39$ & $\$ 38$ & $\$ 29$ & $\$ 34$ & $\$ 35$ & $\$ 37$ & $\$ 35$ & $\$ 39$ & $\$ 41$ & $\$ 39$ & $\$ 43$ \\
\hline 15 & $\$ 38$ & $\$ 38$ & $\$ 37$ & $\$ 30$ & $\$ 34$ & $\$ 35$ & $\$ 37$ & $\$ 33$ & $\$ 39$ & $\$ 40$ & $\$ 38$ & $\$ 42$ \\
\hline 14 & $\$ 36$ & $\$ 35$ & $\$ 36$ & $\$ 28$ & $\$ 33$ & $\$ 35$ & $\$ 37$ & $\$ 32$ & $\$ 39$ & $\$ 40$ & $\$ 37$ & $\$ 40$ \\
\hline 13 & $\$ 36$ & $\$ 34$ & $\$ 36$ & $\$ 31$ & $\$ 34$ & $\$ 35$ & $\$ 38$ & $\$ 36$ & $\$ 42$ & $\$ 43$ & $\$ 40$ & $\$ 41$ \\
\hline 12 & $\$ 37$ & $\$ 34$ & $\$ 36$ & $\$ 34$ & $\$ 36$ & $\$ 36$ & $\$ 39$ & $\$ 39$ & $\$ 44$ & $\$ 46$ & $\$ 42$ & $\$ 43$ \\
\hline 11 & $\$ 36$ & $\$ 32$ & $\$ 35$ & $\$ 31$ & $\$ 33$ & $\$ 36$ & $\$ 38$ & $\$ 39$ & $\$ 46$ & $\$ 44$ & $\$ 39$ & $\$ 42$ \\
\hline 10 & $\$ 33$ & $\$ 30$ & $\$ 33$ & $\$ 29$ & $\$ 32$ & $\$ 35$ & $\$ 38$ & $\$ 39$ & $\$ 45$ & $\$ 45$ & $\$ 39$ & $\$ 42$ \\
\hline 09 & $\$ 32$ & $\$ 26$ & $\$ 31$ & $\$ 27$ & $\$ 31$ & $\$ 34$ & $\$ 37$ & $\$ 37$ & $\$ 41$ & $\$ 45$ & $\$ 42$ & $\$ 41$ \\
\hline 08 & $\$ 25$ & $\$ 23$ & $\$ 30$ & $\$ 26$ & $\$ 31$ & $\$ 33$ & $\$ 36$ & $\$ 34$ & $\$ 36$ & $\$ 39$ & $\$ 38$ & $\$ 39$ \\
\hline 07 & $\$ 27$ & $\$ 20$ & $\$ 28$ & $\$ 25$ & $\$ 30$ & $\$ 33$ & $\$ 35$ & $\$ 33$ & $\$ 33$ & $\$ 36$ & $\$ 33$ & $\$ 38$ \\
\hline 06 & $\$ 34$ & $\$ 24$ & $\$ 29$ & $\$ 25$ & $\$ 30$ & $\$ 33$ & $\$ 33$ & $\$ 26$ & $\$ 24$ & $\$ 29$ & $\$ 28$ & $\$ 37$ \\
\hline 05 & $\$ 34$ & $\$ 28$ & $\$ 30$ & $\$ 25$ & $\$ 30$ & $\$ 32$ & $\$ 33$ & $\$ 23$ & $\$ 23$ & $\$ 29$ & $\$ 31$ & $\$ 37$ \\
\hline 04 & $\$ 35$ & $\$ 29$ & $\$ 31$ & $\$ 27$ & $\$ 31$ & $\$ 32$ & $\$ 32$ & $\$ 20$ & $\$ 20$ & $\$ 28$ & $\$ 29$ & $\$ 36$ \\
\hline 03 & $\$ 38$ & $\$ 31$ & $\$ 31$ & $\$ 26$ & $\$ 33$ & $\$ 33$ & $\$ 32$ & $\$ 21$ & $\$ 20$ & $\$ 28$ & $\$ 30$ & $\$ 37$ \\
\hline 02 & $\$ 40$ & $\$ 34$ & $\$ 32$ & $\$ 28$ & $\$ 34$ & $\$ 34$ & $\$ 33$ & $\$ 24$ & $\$ 22$ & $\$ 29$ & $\$ 30$ & $\$ 38$ \\
\hline \multirow[t]{2}{*}{01} & $\$ 43$ & $\$ 37$ & $\$ 34$ & $\$ 29$ & $\$ 36$ & $\$ 35$ & $\$ 35$ & $\$ 28$ & $\$ 27$ & $\$ 29$ & $\$ 31$ & $\$ 39$ \\
\hline & \multicolumn{12}{|c|}{ Uttar Pradesh (\$/MWh) } \\
\hline 24 & $\$ 56$ & $\$ 48$ & $\$ 39$ & $\$ 32$ & $\$ 39$ & $\$ 43$ & $\$ 36$ & $\$ 33$ & $\$ 31$ & $\$ 33$ & $\$ 34$ & $\$ 42$ \\
\hline 23 & $\$ 51$ & $\$ 50$ & $\$ 43$ & $\$ 41$ & $\$ 45$ & $\$ 46$ & $\$ 39$ & $\$ 41$ & $\$ 39$ & $\$ 47$ & $\$ 46$ & $\$ 49$ \\
\hline 22 & $\$ 49$ & $\$ 47$ & $\$ 41$ & $\$ 44$ & $\$ 50$ & $\$ 50$ & $\$ 42$ & $\$ 39$ & $\$ 43$ & $\$ 55$ & $\$ 45$ & $\$ 53$ \\
\hline 21 & $\$ 45$ & $\$ 46$ & $\$ 42$ & $\$ 48$ & $\$ 53$ & $\$ 50$ & $\$ 44$ & $\$ 43$ & $\$ 50$ & $\$ 69$ & $\$ 50$ & $\$ 54$ \\
\hline 20 & $\$ 40$ & $\$ 41$ & $\$ 39$ & $\$ 42$ & $\$ 51$ & $\$ 46$ & $\$ 44$ & $\$ 39$ & $\$ 42$ & $\$ 51$ & $\$ 43$ & $\$ 52$ \\
\hline 19 & $\$ 37$ & $\$ 39$ & $\$ 36$ & $\$ 32$ & $\$ 37$ & $\$ 40$ & $\$ 45$ & $\$ 41$ & $\$ 45$ & $\$ 51$ & $\$ 40$ & $\$ 42$ \\
\hline 18 & $\$ 44$ & $\$ 47$ & $\$ 37$ & $\$ 28$ & $\$ 34$ & $\$ 42$ & $\$ 43$ & $\$ 47$ & $\$ 48$ & $\$ 47$ & $\$ 39$ & $\$ 39$ \\
\hline 17 & $\$ 47$ & $\$ 50$ & $\$ 41$ & $\$ 29$ & $\$ 34$ & $\$ 43$ & $\$ 38$ & $\$ 45$ & $\$ 42$ & $\$ 50$ & $\$ 44$ & $\$ 41$ \\
\hline 16 & $\$ 46$ & $\$ 49$ & $\$ 43$ & $\$ 30$ & $\$ 35$ & $\$ 42$ & $\$ 38$ & $\$ 44$ & $\$ 41$ & $\$ 45$ & $\$ 43$ & $\$ 44$ \\
\hline 15 & $\$ 45$ & $\$ 49$ & $\$ 42$ & $\$ 30$ & $\$ 36$ & $\$ 45$ & $\$ 38$ & $\$ 43$ & $\$ 42$ & $\$ 49$ & $\$ 49$ & $\$ 43$ \\
\hline 14 & $\$ 43$ & $\$ 47$ & $\$ 40$ & $\$ 28$ & $\$ 34$ & $\$ 46$ & $\$ 38$ & $\$ 43$ & $\$ 44$ & $\$ 49$ & $\$ 45$ & $\$ 41$ \\
\hline 13 & $\$ 43$ & $\$ 45$ & $\$ 39$ & $\$ 31$ & $\$ 35$ & $\$ 44$ & $\$ 38$ & $\$ 47$ & $\$ 46$ & $\$ 66$ & $\$ 52$ & $\$ 44$ \\
\hline 12 & $\$ 43$ & $\$ 42$ & $\$ 38$ & $\$ 36$ & $\$ 37$ & $\$ 44$ & $\$ 40$ & $\$ 53$ & $\$ 48$ & $\$ 57$ & $\$ 56$ & $\$ 45$ \\
\hline 11 & $\$ 41$ & $\$ 38$ & $\$ 35$ & $\$ 31$ & $\$ 33$ & $\$ 40$ & $\$ 39$ & $\$ 51$ & $\$ 49$ & $\$ 66$ & $\$ 56$ & $\$ 47$ \\
\hline 10 & $\$ 39$ & $\$ 35$ & $\$ 33$ & $\$ 30$ & $\$ 32$ & $\$ 38$ & $\$ 39$ & $\$ 50$ & $\$ 50$ & $\$ 73$ & $\$ 58$ & $\$ 45$ \\
\hline 09 & $\$ 36$ & $\$ 30$ & $\$ 31$ & $\$ 28$ & $\$ 31$ & $\$ 35$ & $\$ 38$ & $\$ 47$ & $\$ 44$ & $\$ 56$ & $\$ 49$ & $\$ 43$ \\
\hline 08 & $\$ 30$ & $\$ 27$ & $\$ 30$ & $\$ 26$ & $\$ 31$ & $\$ 35$ & $\$ 36$ & $\$ 37$ & $\$ 37$ & $\$ 44$ & $\$ 44$ & $\$ 39$ \\
\hline 07 & $\$ 33$ & $\$ 28$ & $\$ 28$ & $\$ 26$ & $\$ 30$ & $\$ 34$ & $\$ 35$ & $\$ 36$ & $\$ 33$ & $\$ 39$ & $\$ 36$ & $\$ 38$ \\
\hline 06 & $\$ 40$ & $\$ 34$ & $\$ 29$ & $\$ 25$ & $\$ 30$ & $\$ 37$ & $\$ 33$ & $\$ 28$ & $\$ 24$ & $\$ 34$ & $\$ 33$ & $\$ 38$ \\
\hline 05 & $\$ 49$ & $\$ 38$ & $\$ 31$ & $\$ 25$ & $\$ 32$ & $\$ 42$ & $\$ 33$ & $\$ 27$ & $\$ 23$ & $\$ 29$ & $\$ 31$ & $\$ 37$ \\
\hline 04 & $\$ 51$ & $\$ 40$ & $\$ 33$ & $\$ 27$ & $\$ 33$ & $\$ 44$ & $\$ 32$ & $\$ 23$ & $\$ 20$ & $\$ 28$ & $\$ 29$ & $\$ 36$ \\
\hline 03 & $\$ 52$ & $\$ 42$ & $\$ 32$ & $\$ 27$ & $\$ 34$ & $\$ 45$ & $\$ 32$ & $\$ 24$ & $\$ 20$ & $\$ 28$ & $\$ 30$ & $\$ 37$ \\
\hline 02 & $\$ 52$ & $\$ 43$ & $\$ 33$ & $\$ 28$ & $\$ 35$ & $\$ 42$ & $\$ 34$ & $\$ 27$ & $\$ 22$ & $\$ 29$ & $\$ 31$ & $\$ 38$ \\
\hline 01 & $\$ 53$ & $\$ 47$ & $\$ 36$ & $\$ 29$ & $\$ 36$ & $\$ 42$ & $\$ 36$ & $\$ 31$ & $\$ 27$ & $\$ 30$ & $\$ 31$ & $\$ 39$ \\
\hline
\end{tabular}


Table 4 provides a more detailed breakdown of average prices. Each column represents the average 24-hour price profile for the month. High prices for the day tended to occur an hour after sunset, consistent with peak demand in both Bihar and Nepal. Only during the evening hours of the late monsoon season (mid-August to mid-September) and the middle of the dry season (midMarch to mid-April) did market prices consistently reach $\$ 50 / \mathrm{MWh}$. In only 86 hours-less than $1 \%$ of the time-were IEX prices for Bihar higher than the tariff rate currently governing CBET from Bihar to Nepal.

\subsection{Existing Energy Trading}

Power exchanges largely flowed to Nepal for 2016-2017. Volume followed the ebb in net generation from Nepal's domestic hydropower resources during the dry season, as shown in Table 5. About $90 \%$ of the power Nepal imported from India flowed across the Eastern Tarai (POSOCO 2017a and 2017b).

Table 5. Distribution of Nepal's Electricity Imports, by Month

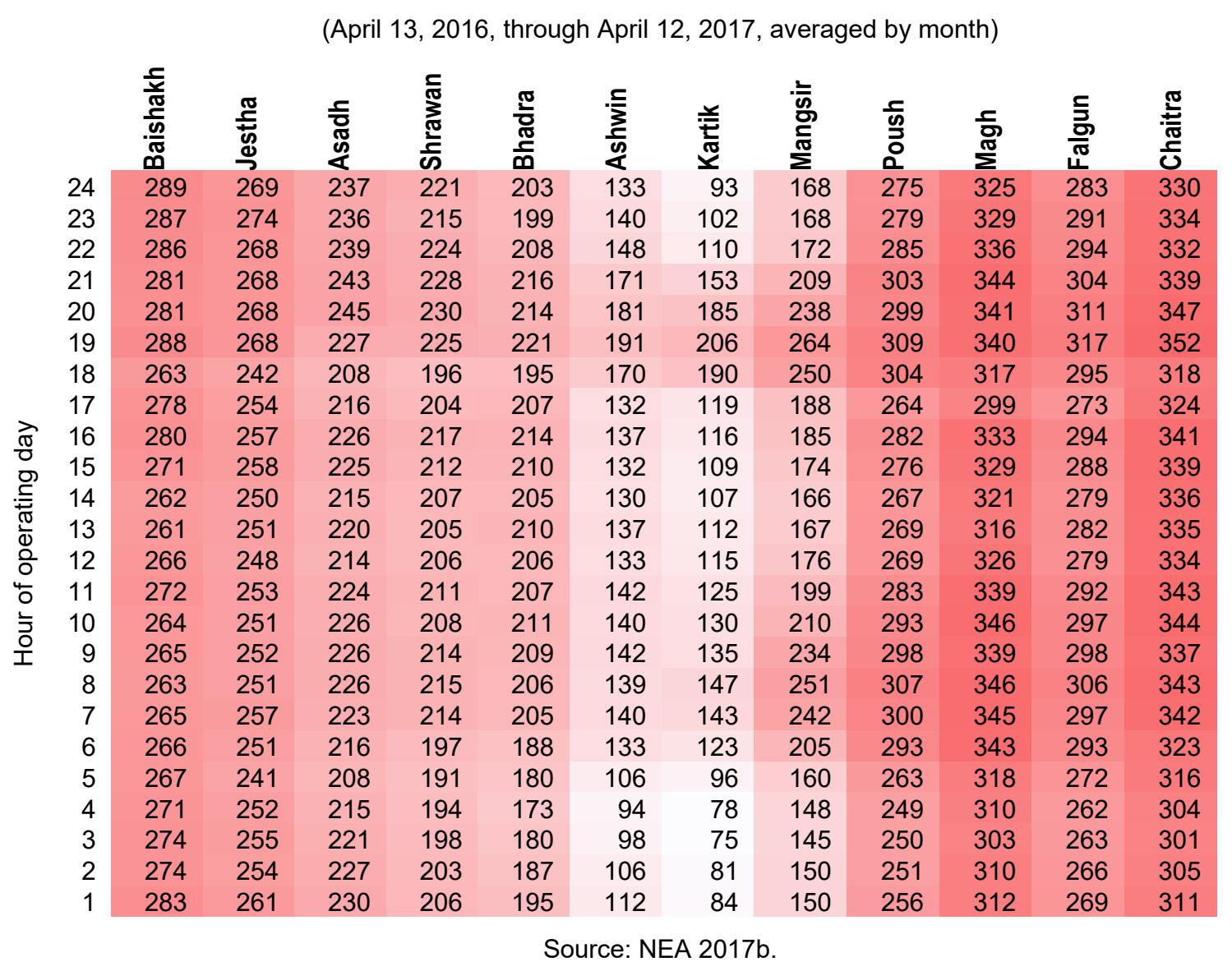




\subsection{Impact of Load Shedding on the Value of Imports}

Load shedding in Nepal is currently a major factor affecting CBET in the post-earthquake electricity market. Power imported from India is key to NEA's strategy for reducing the impact of load shedding, particularly during the post-monsoon months and the dry season. The country's total domestic generation from Magh to Jestha (mid-January to mid-June) was one-half to twothirds of its maximum generation during the monsoon and post-monsoon season. This coincided with maximum imports from India.

Two uncertainties complicate an analysis of load shedding. First is the difficulty of calculating how many megawatts of customer demand are actually lost when a specific substation or feeder line is taken out of service. Equipment power ratings might be known, but actual usage that is foregone might not be. The second problem is that NEA does not have an estimate of Nepal's value of lost load (VOLL), so even if the quantity of lost load were known, its value still would not be. NEA also does not offer an interruptible tariff from which VOLL may be inferred.

Estimating VOLL is challenging even for the world's most advanced power markets. Systemwide VOLL estimates in U.S. markets range from around $\$ 10,000 / \mathrm{MWh}$ to $\$ 14,000 / \mathrm{MWh}$ (London Economics 2013). Where VOLL is estimated separately for customer classes, it can reach $\$ 30,000 / \mathrm{MWh}$ or more for commercial and industrial customers. In some markets, VOLL is inferred from existing tariff rates.

While there is no convention for adapting VOLL from one country to another, adjusting existing estimates using gross domestic product (GDP) per capita can provide a crude and general approximation of how VOLL estimates in the United States might economically compare in Nepal (for GDP per capita, see World Bank 2017). Using this adjustment, the equivalent values in Nepal are about three times higher than the cost of importing power from India for the purpose of reducing load shedding. When considering commercial and industrial load only, the adjusted VOLL is around 10 times higher.

Therefore, a major question affecting the value of options for future CBET is when load shedding will cease. The economic drivers could change significantly at that point, altering the balances of supply and demand that affect which cross-border transmission paths are most likely to have the greatest long-term value. 


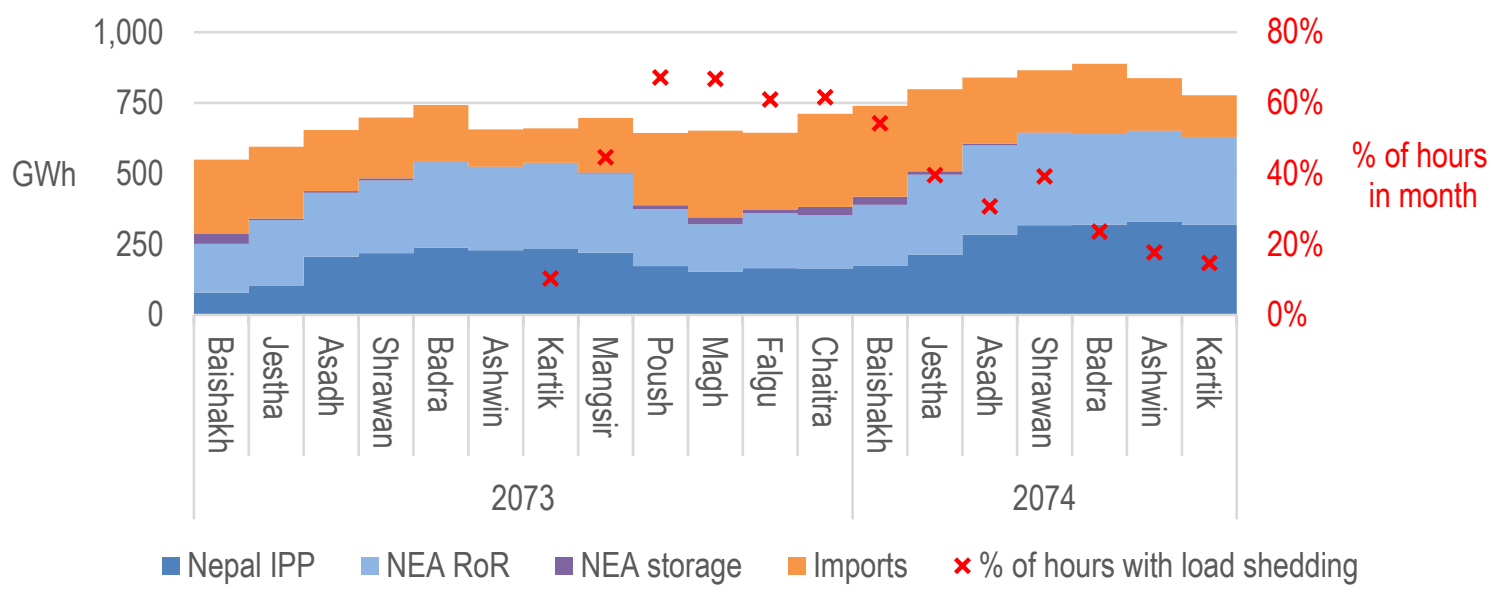

Figure 9. Monthly generation for Nepal, by resource type.

Source: Compiled from NEA 2017b. Note: Load shedding was not reported prior to Kartik 2073.

Figure 9 shows the generation resources used to serve load in Nepal from mid-April 2016 through mid-November 2017, corresponding to the 2073 Nepalese calendar year and the first seven months of the 2074 calendar year. The data show that load shedding was frequent in Poush (mid-December to mid-January) and began to abate in Jestha (mid-May through mid-June) with the beginning of the monsoon season and a corresponding increase in domestic hydro generation. Domestic generation for the seven months ending in Kartik 2074 (mid-April through midNovember 2017) was 30\% higher than for the same period a year earlier. ${ }^{8}$ Imported power was $18 \%$ higher.

The month with the most frequent recorded load shedding during the period examined was Magh (mid-January to mid-February). In the absence of data on total customer demand and actual lost load, this analysis uses Magh as a test for critical load shedding trends in Nepal. In the average daily profile for that month, the peak volume of load served typically occurred during the hour ending at 7 p.m., which we use here for testing supply and demand trends affecting future load shedding. Average load served for this test hour was 833 MW (NEA 2017b).

Table 6 and Figure 10 show the domestic generation resources that were typically available during the test hour. Imports from India used to supplement domestic generation at this time averaged $340 \mathrm{MW}$, or about $41 \%$ of average energy delivered to load. The higher availability of NEA hydro- $66 \%$ - reflects NEA's operating strategy of reducing early morning and midday operation levels at its own peaking RoR hydro resources and increasing its generation during the mid-morning and evening hours.

\footnotetext{
${ }^{8}$ NEA reports operations data by Nepalese months. We retain that time aggregation here.
} 
Table 6. Domestic Generation Available for Critical Load Shedding Hours in Nepal

\begin{tabular}{|c|c|c|c|c|c|}
\hline & \multicolumn{2}{|c|}{$\begin{array}{l}\text { Energy Served, } 6 \text { p.m. to } \\
7 \text { p.m. Period, Magh } 2073^{*}\end{array}$} & \multicolumn{3}{|c|}{$\begin{array}{l}\text { Projected Capacity Available for } \\
\text { Dry-Season Peak Demand (MW) }\end{array}$} \\
\hline & Average $M W$ & $\begin{array}{c}\% \text { of } \\
\text { Nameplate }\end{array}$ & 2018 & 2019 & 2020 \\
\hline NEA hydro & 252 & $66 \%$ & 281 & 582 & 622 \\
\hline NEA storage & 74 & $80 \%$ & 85 & 85 & 85 \\
\hline IPP hydro & 168 & $38 \%$ & 257 to 398 & 290 to 484 & 333 to 596 \\
\hline Total & 493 & & $\begin{array}{c}623 \text { to } \\
764\end{array}$ & $\begin{array}{l}957 \text { to } \\
1,151\end{array}$ & $\begin{array}{c}1,040 \text { to } \\
1,303\end{array}$ \\
\hline Imports & 340 & & & & \\
\hline $\begin{array}{l}\text { Availability for } \\
\text { peak load, holding } \\
\text { imports constant }\end{array}$ & 833 & & $\begin{array}{l}963 \text { to } \\
1,104\end{array}$ & $\begin{array}{l}1,297 \text { to } \\
1,491\end{array}$ & $\begin{array}{l}1,380 \text { to } \\
1,643\end{array}$ \\
\hline
\end{tabular}

${ }^{*}$ Corresponds to Jan. 14 to Feb. 12, 2017.

Notes on table assumptions and methodology: "Projected capacity available for dry-season peak demand" is the nameplate MW projected by NEA to be online for the indicated year, multiplied by the percentages in column 3 .

Projections for new IPP capacity are taken from NEA 2017c and only include projects under construction that have closed on financing.

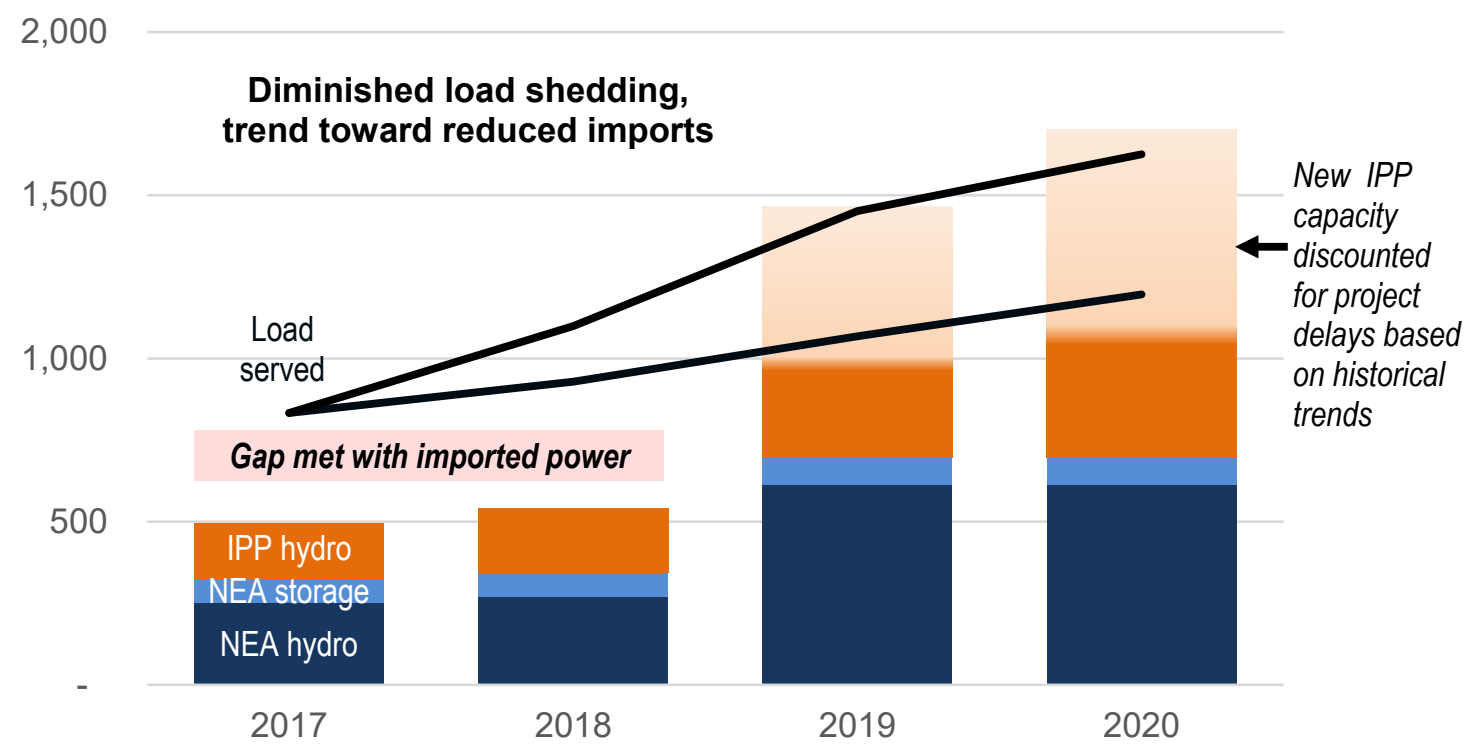

Figure 10. Short-term projection of supply and served load for test hour.

Source: NEA 2014, WECS 2017. Note: "Load served" excludes unserved load (load shedding). Load served for 2017 is projected forward hypothetically using two growth rates projected by the Nepal Water and Energy Commission

Secretariat (WECS). The low growth curve is the WECS reference scenario, based on annual economic growth of $7.2 \%$. The high growth curve assumes $9.2 \%$ economic growth plus short-term policy interventions by the Government of Nepal. 
NEA's projected amount of new capacity from 2018 to 2020 indicates a potential for greater resource availability - and, therefore, reduced load shedding - during the dry season. The largest NEA project currently under construction is the 456-MW Upper Tamakoshi hydroelectric project, which is scheduled to be online in early 2019 (NEA 2017a). Upper Tamakoshi, along with new hydro capacity from IPPs, could double Nepal's domestic generating capacity available during the dry season by 2019 . These numbers suggest that for the test hour, resource availability could increase at an annual rate of $19 \%$ to $26 \%$ from 2018 to 2020 .

NEA uses load growth projections by Nepal's Water and Electricity Commission Secretariat, which models economic growth and national energy consumption under various assumptions. Its reference scenario assumes annual economic growth of $7.2 \%$ and shows electricity demand growing $15.1 \%$ annually from 2015 to 2020 and $12.2 \%$ annually from 2020 to 2025 . The commission also modeled demand with $9.2 \%$ economic growth accompanied by targeted policy interventions by the government. This scenario results in $31.7 \%$ annual demand growth from 2015 to 2020 (boosted by assumed policy interventions), leveling off to $9.7 \%$ annual demand growth from 2020 to 2025 .

Figure 10 applies these two growth trajectories to total load served (domestic generation plus imports) for the test hour. In this figure, the gap between the line representing load served and the domestic supply stack approximates the projected use of imports for the test hour. A smaller gap implies less need for load shedding, holding imported power constant.

The gap shrinks considerably in 2019 , largely due to the projected completion of Upper Tamakoshi (NEA 2017a). The chart suggests that in 2019, Nepal's domestic generation could meet nearly all of the demand that was served in 2017, depending on overall economic growth. (For reasons previously discussed in this section, the point at which load shedding could end completely is difficult to predict due to the lack of data on actual lost load for 2017.)

One important variable will be the actual pace of capacity additions from IPPs. Delays and cancellations can happen even if the project has secured financing and is under construction. For example, of all IPP capacity with an expected commercial operation date of 2016 , only $38 \%$ was actually online in 2017 (NEA 2017b and 2017c). Therefore, to account for possible project delays and attrition, Table 6 and Figure 10 show new IPP capacity as a range. The high value is the nameplate capacity of all generators expected to be online, while the low value discounts new generation for each year by $38 \%$.

The consequence for CBET between India and Nepal is that load shedding is not likely to be a major driver for trades from India to Nepal in the near future and could cease to be so well within the time it would take to build a new transmission line between the two countries. The economic benchmark for the value of imports will no longer be Nepal's VOLL, which, while unspecified, is effectively higher than the tariff prices governing flows from India to Nepal. The value of future CBET - and, therefore, of new transmission supporting it — will most likely be determined by ordinary market factors. 


\subsection{Eastern Tarai CBET}

Existing connections across the Eastern Tarai CBET area include three 132-kV lines and four 33$\mathrm{kV}$ lines. Net power trades from India to Nepal over these paths amounted to 1,869 GWh for the 12 months ending in March 2017, an increase of 46\% from the previous year (POSOCO 2017a).

Plans for new generation capacity east of the Butwal flowgate appear to be outpacing the anticipated growth in electricity demand in Nepal. IPPs are expected to add between $400 \mathrm{MW}$ and 1,000 MW of new generation between 2017 and 2020, along with the 544 MW NEA plans to add itself. This would increase the eastern grid's total capacity by an average of $36 \%$ to $59 \%$ per year, depending on project delays.

Bihar, the state bordering most of the Eastern Tarai, historically has been a net importer of power from other parts of the Eastern RLDC region. Bihar was 19\% of the region's average load for the year ending March 2017 but provided only 6\% of regional generation (POSOCO 2017a). About $92 \%$ of the Eastern RLDC region's generation for the year ending March 2017 came from coal, with nearly all of the remainder coming from hydro.

Growth in the region's generation capacity has been keeping pace with demand, with about $60 \%$ of the additions in 2016 coming from new thermal generators and the rest from new hydro. As of July 2017, the region also had about 1,000 MW of renewables, nearly half of which was bagasse processing in West Bengal.

The Eastern RLDC currently has surplus supply for most of the year, enabling it to export upwards of 20 TWh to the Northern RLDC. The eastern region's highest peak demand was 19.6 GW in March 2017. Its total effective generating capacity was $30.9 \mathrm{GW}$, giving it a large effective reserve margin of nearly 58\% (POSOCO 2017a, CEA 2016a, CEA 2016b). ${ }^{9}$

Bihar, West Bengal, and Odisha have a significant amount of load-driven up-ramping during the three hours before evening peak. Figure 11 shows the average daily load profile by month for Bihar. Low demand in the late afternoon followed by high demand after sundown often results in about 1,000 MW of up-ramping in the early evening hours of winter. Load analysis data for all states in the Eastern RLDC region show a pattern of about 5,000 MW of coincident ramping in November over the three hours prior to peak, about one-quarter of that occurring in Bihar (POSOCO 2016).

During this same month, the Eastern RLDC region's 5,759 MW of hydro resources ran at about half the pace they did in September and October. This suggests that some of the region's ramping requirements in November 2016 might have been provided by resources other than hydro-possibly coal units, which have limited ramping capability.

\footnotetext{
${ }^{9}$ Effective generating capacity was obtained by adjusting the region's installed capacity of coal/lignite and hydro $(31.4 \mathrm{GW}$ and $5.8 \mathrm{GW})$ by the most recent all-India forced outage rates for these technologies $(19 \%$ and $5 \%)$, as reported by India's Central Electricity Authority.
} 


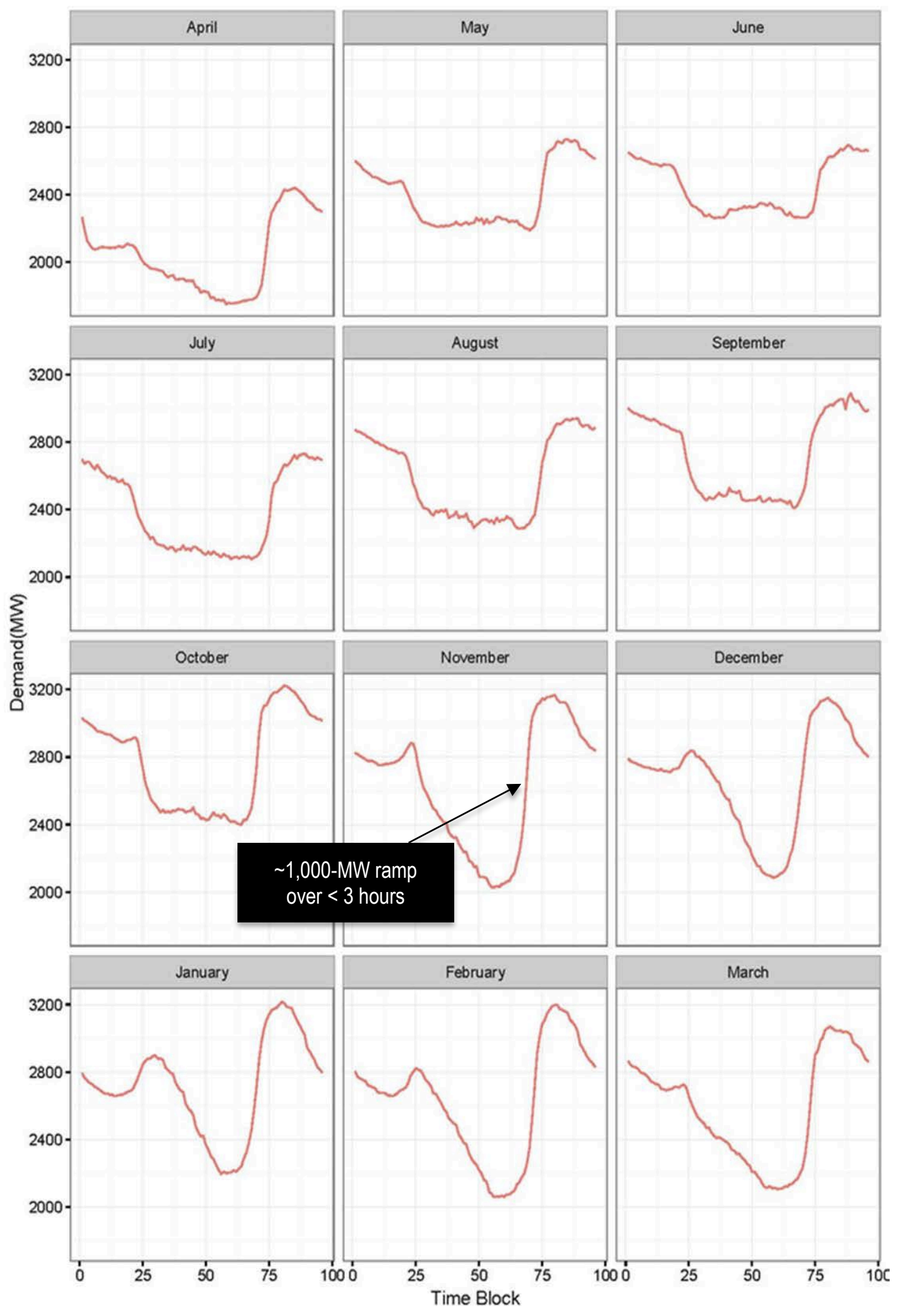

Figure 11. Daily load profiles for Bihar, by month.

Source: POSOCO 2016. 
As demand throughout the Eastern RLDC region increases, the ramping burden during these months could require operational flexibility that the region's coal units might not be capable of providing as cost-effectively as imports might. This could provide a high-value opportunity for power exports from Nepal to the Eastern RLDC region as more of Nepal's hydropower comes online.

One factor that could increase the flow of power from Nepal across the Eastern Tarai is potential demand in Bangladesh. Both countries have been investigating hydro development in Nepal for use in Bangladesh (The Independent 2017). However, India's guidelines for CBET might prevent a direct exchange between Nepal and Bangladesh. Transfers and prices that are determined administratively through Indian intermediaries could both increase transaction costs and result in less efficient power dispatch.

\section{Major Bilateral Project: Arun 3} (Estimated online date: 2023)

SJVN Ltd., a power producer owned by the Government of India and the State Government of Himachal Pradesh, is developing the 900-MW Arun 3 hydroelectric project in eastern Nepal. The Indian government approved the project in early 2017, and work has begun on land acquisition, transmission, roads, and other infrastructure for construction. (Subedi 2017).

Under the memorandum of understanding between the Government of Nepal and SJVN, Nepal would receive an estimated 800 GWh of power from the project annually, which is slightly more than NEA's annual

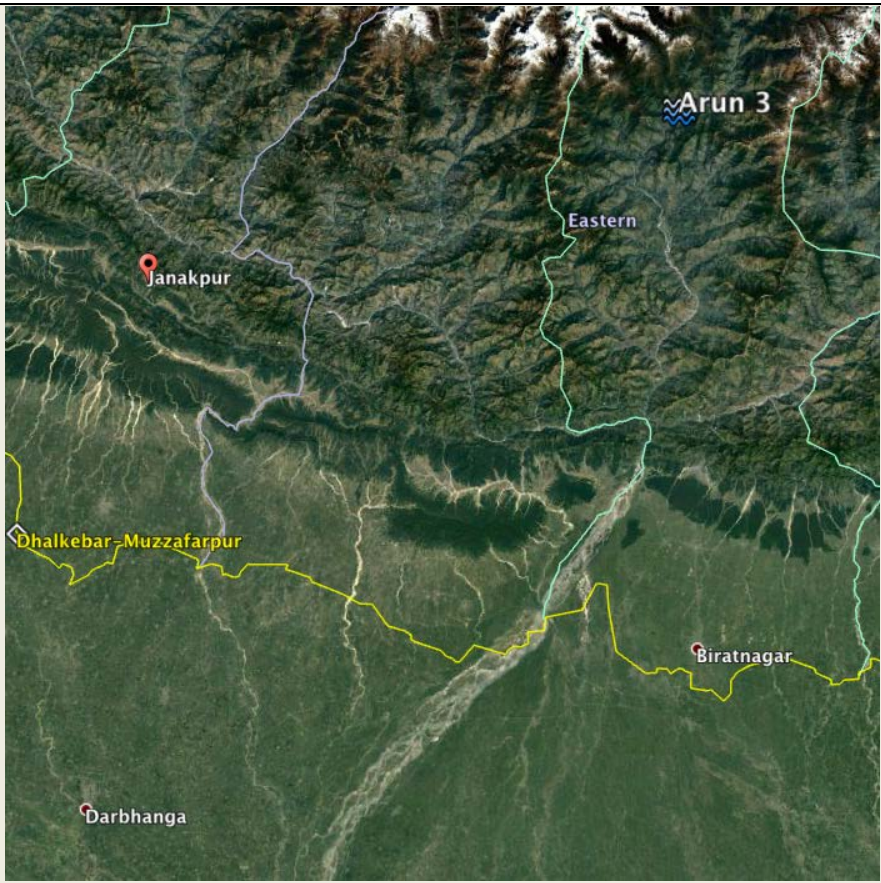
sales in its Biratnagar region. The balance would flow into Bihar via a dedicated $400-\mathrm{kV}$ transmission line from Dhalkebar on the border to Muzzafarpur. Another dedicated 400-kV line would carry power from Arun 3 to Dhalkebar (IBN 2017).

\subsection{Western Tarai CBET}

Net flows across the Western Tarai CBET - nearly all of it on the Tanakpur-Mahendranagar connection-amounted to $190 \mathrm{GWh}$ for the 12 months ending April 2017, much less than the volume traded across the Eastern Tarai CBET (POSOCO 2017b). Imports into Nepal slowed significantly during the post-monsoon months of October and November, with the volume dropping to less than one-third the pace of the rest of the year.

Nepal's western grid was a net importer of energy throughout the 2016-2017 year. The region had about 34 MW of generating capacity, most of it owned by IPPs. The three largest hydro stations - which account for more than three-fourths of the Western region's grid capacity- 
generated about 127 GWh of energy for the year ending April 12, 2017, 27\% as much electricity as NEA sold through its two western offices (NEA 2017a and 2017b).

NEA plans to add $30 \mathrm{MW}$ in the Western region, and new IPP capacity could amount to another $37 \mathrm{MW}$ to $97 \mathrm{MW}$ by 2020 . If these additions operate comparably to the region's existing capacity, they could shift the western NEA grid from being a net importer of electricity to a position in which internal generation is about the same as consumption.

Uttar Pradesh is the Northern RLDC region's largest load center with $31 \%$ of total regional demand. Coal is the Northern RLDC's largest generation source, although with a $65 \%$ share of the mix it is not as dominant as is the case for the Eastern RLDC. Hydro provided $26 \%$ of the Northern region's power (compared to less than $8 \%$ in the Eastern RLDC region), with the remainder divided among nuclear, natural gas, and a growing share of wind and solar (POSOCO 2017b).

Rapid development of wind and solar power is another contrast between the Northern RLDC and the Eastern RLDC regions. Most of the Northern RLDC region's activity has been in Rajasthan, which as of April 2017 had $1.8 \mathrm{GW}$ of solar capacity and 3.9 GW of wind capacity. Uttar Pradesh and Uttarakhand had another $314 \mathrm{MW}$ of solar photovoltaic (PV). Higher penetrations of wind and solar PV will increase the Northern RLDC's need for flexible resources, which could increase the value of power from flexible hydro resources in Nepal across the Western Tarai CBET area.

\section{Major Bilateral Project: Upper Karnali \\ (No estimated online date)}

GMR, a private infrastructure developer headquartered in New Delhi, is negotiating a finance package for the 900-MW Upper Karnali hydroelectric project, located in western Nepal. As of this writing, the firm had requested additional time to close on project financing (Subedi 2017).

Nepal would get more than $400 \mathrm{GWh}$ per year under the terms of GMR's agreement with the Government of Nepal, which is slightly less than the 482 GWh that NEA sold west of Butwal in its Attariya and Nepalganj regions in 2016-2017. This, combined with other capacity additions that

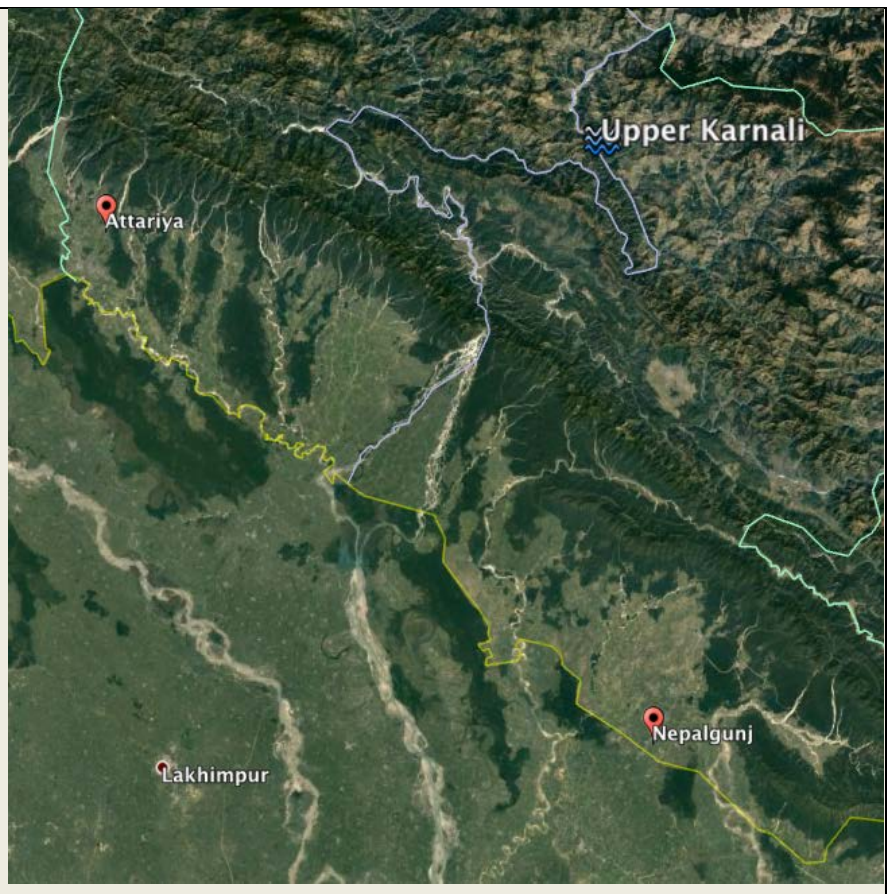
are expected to be online by 2020 , could put the region in a position of being a net exporter, excluding the power that GMR would export into the Northern RLDC region (IBN 2017). 


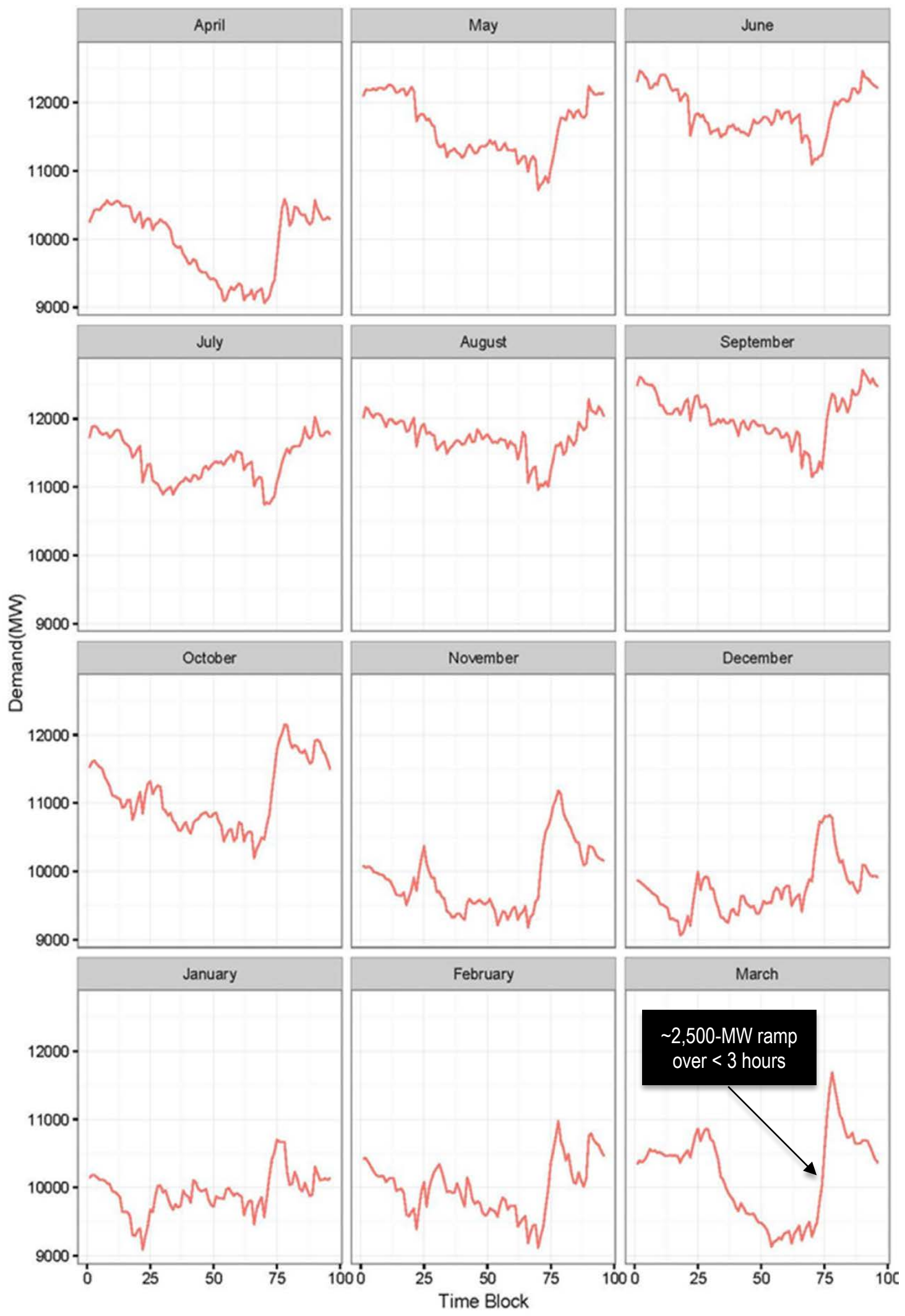

Figure 12. Daily load profiles for Uttar Pradesh, by month.

Source: POSOCO 2016. 
Figure 12 shows that demand in Uttar Pradesh during March tends to increase by nearly 2,500 MW in less than three hours around sunset. Evening ramping can also be significant during other months (POSOCO 2016). Thus, while the Northern RLDC region has more flexible hydro capacity than the Eastern region has, the need for such flexibility - as reflected in seasonal ramping requirements - is much larger in Uttar Pradesh than in Bihar.

\subsection{Discussion}

The detailed analysis of this section supports the following conclusions:

1. Load shedding in Nepal will most likely cease to be a driver for CBET between India and Nepal within the time it would take to build a new transmission line.

A. In the first post-earthquake calendar year, the dominant driver for CBET was load shedding in Nepal. While the true VOLL remains undetermined, Nepal's policy of relying on imports to relieve load shedding implies that the value per MWh was higher than the tariff prices governing CBET. This is consistent with practices elsewhere in the world, including markets where the value of lost load has been calculated.

B. Once Nepal has sufficient internal resources to minimize load shedding, the implicit VOLL will no longer be the primary factor behind the value of CBET economics. The tariff rate that currently governs most CBET across the Eastern Tarai could then begin to suppress further bulk trades of energy from Bihar to Nepal.

2. Market fundamentals and longer-term trends for Indo-Nepalese CBET appear to favor connections to India's Northern RLDC region, which tends to be a net importer of electricity. Upgrading the Butwal-Gorakhpur path is consistent with the likely value propositions.

A. Butwal to Gorakhpur appears to be the highest-value path for new CBET transmission in the near future. This path provides access to India's Northern RLDC region and has already been identified as a priority for transmission development (GoI/GoN 2017, MCC 2017). Wholesale prices in Uttar Pradesh are generally higher than in Bihar, and the Northern RLDC area is rapidly increasing its use of large-scale wind power and PV. Greater use of variable renewable resources tends to increase the need for grid flexibility, which reservoir storage and peaking RoR hydro can provide.

B. In contrast, in the Eastern RLDC region, low market prices in Bihar could limit bulk trades of hydropower from Nepal to Bihar. The rate currently paid by NEA to IPPs for peaking RoR hydro - around $\$ 47 / \mathrm{MWh}$ in the wet season from June to November, and up to $\$ 103 / \mathrm{MWh}$ during the dry season - is consistently higher than market prices in Bihar, except in the early evening hours from mid-August to mid-September (NEA 2017a). However, production cost modeling could provide additional insights about the effect CBET across the Eastern Tarai might have on the redistribution of power flows in the Eastern RLDC region. This could reveal hidden CBET potential value. 
3. While connections across the Western Tarai area could further increase mutually beneficial CBET opportunities, doing so could depend on system upgrades within Nepal to increase the capacity to move between Butwal and Nepalganj.

A. The Western Tarai CBET could offer significant economic potential for mutually beneficial power exchanges. However, Nepal's ability to take full advantage of CBET opportunities across the Western Tarai might depend on internal transmission development in conjunction with new cross-border transmission. The existing transmission flowgate at Butwal could limit the ability of generators in eastern Nepal to sell into India's higher-priced Northern RLDC region via Nepalganj and Attariya. One question for PCM is whether the Butwal-toNepalganj path would be congested under future load growth scenarios. Specifically, would the proposed 400-kV interconnection from Butwal to Gorakhpur be sufficient for economic deliveries from eastern Nepal into Uttar Pradesh, or would congestion on the path from Butwal to Nepalganj indicate the benefit of expanding that internal path? (This will be tested more rigorously in the production cost modeling phase of this project.)

4. Maximizing the value of any new transmission intended to enhance CBET could depend on bilateral tariff reform and greater operational coordination between Nepal and India.

A. India's growing need for system flexibility could create new CBET value on both sides of the border. This, however, will most likely depend on efficient real-time price formation, which in turn could depend on greater integration of grid operations and markets. Unlike bulk power sales, deployment of flexibility resources is an hourly_even subhourly_optimization task. If peaking RoR and storage hydroelectric projects in Nepal are to be an additional source of flexibility for renewable energy development in India's Northern RLDC region, CBET interties along the Western Tarai will need an operational status equivalent to other parts of the Indian grid.

B. Indian energy developers are already looking to Nepal for new hydro capacity serving the Eastern and Northern RLDC regions, as exemplified by the Arun 3 and Upper Karnali projects. Both are planned as peaking RoR hydro. The value to the Eastern RLDC lies primarily in additional operational flexibility: the resource mix is currently 92\% coal and load in Bihar and West Bengal have severe upramping requirements in the evenings. The value to the Northern RLDC lies in the ability to integrate a growing portfolio of wind and solar in Rajasthan, along with seasonal load ramping needs. With greater operational coordination between India and Nepal, other hydro resources in Nepal could supplement the flexibility value provided by the Arun 3 and Upper Karnali projects.

5. Next steps

A. The question of whether the benefits of added flexibility would be enough to warrant additional transmission connections across the Eastern or Western Tarai would need to be examined in greater detail through PCM. Reduced CBET due to reduced load shedding in Nepal would leave more capacity available on existing cross-border transmission. Whether that is likely to be enough will depend on 
Nepal's mix of flexible peaking RoR hydro and less-flexible RoR hydro, the timing of load ramps, power flows elsewhere in India, and other factors.

B. PCM can test load growth and capacity growth scenarios that could accelerate or delay the need for new cross-border transmission. PCM can also compare two paths for moving hydropower from Nepal to the Northern RLDC region: via Butwal, or via the Western Tarai, assuming expansion of the Butwal flowgate within Nepal.

C. All these factors tend to increase the uncertainty and risk of new transmission projects intended to support CBET. Whether new transmission would be used and useful would depend on energy prices - and on whether generators can respond to them. The fixed rate governing CBET pricing could distort the price signals, although tariff reforms allowing market-based CBET pricing could help. Such reforms would increase the opportunities for hedging and other measures to manage risk. A broad application of reform would include ensuring the ability of IPPs in Nepal to submit energy offers into India's power markets, and the ability of industrial customers in Nepal's Eastern Tarai to participate in any current or future demand response programs managed through the Eastern RLDC operations. Similarly, market liberalization between Nepal, India's Eastern RLDC area, and Bangladesh could increase regional flows in an economically efficient manner. Without such market liberalization, the economic rationale for expanding the existing transmission infrastructure across the Eastern Tarai to support CBET could be limited. 


\section{Variations in Construction Costs}

Terrain characteristics can affect the cost of building new transmission, which in turn can affect the balance between costs and benefits among transmission expansion options. This section reports the results of a geographic information systems (GIS) analysis of likely CBET interconnection points along the Indo-Nepalese border and how they might vary with respect to the cost of construction. The analysis focuses on the physical attributes of the surrounding area, and not on legal or economic issues such as right-of-way or local land values.

The map in Figure 13 shows the eight major interconnection points that currently exist on the border. It was assumed for the GIS analysis that the most likely form of CBET-related transmission expansion would be to upgrade these existing interconnections to $400 \mathrm{kV}$, as these points already have connecting substations identified on the Indian and Nepalese grids. One point—Dhalkebar to Muzzafarpur-was excluded from the analysis because the necessary infrastructure for $400-\mathrm{kV}$ service is already in place.

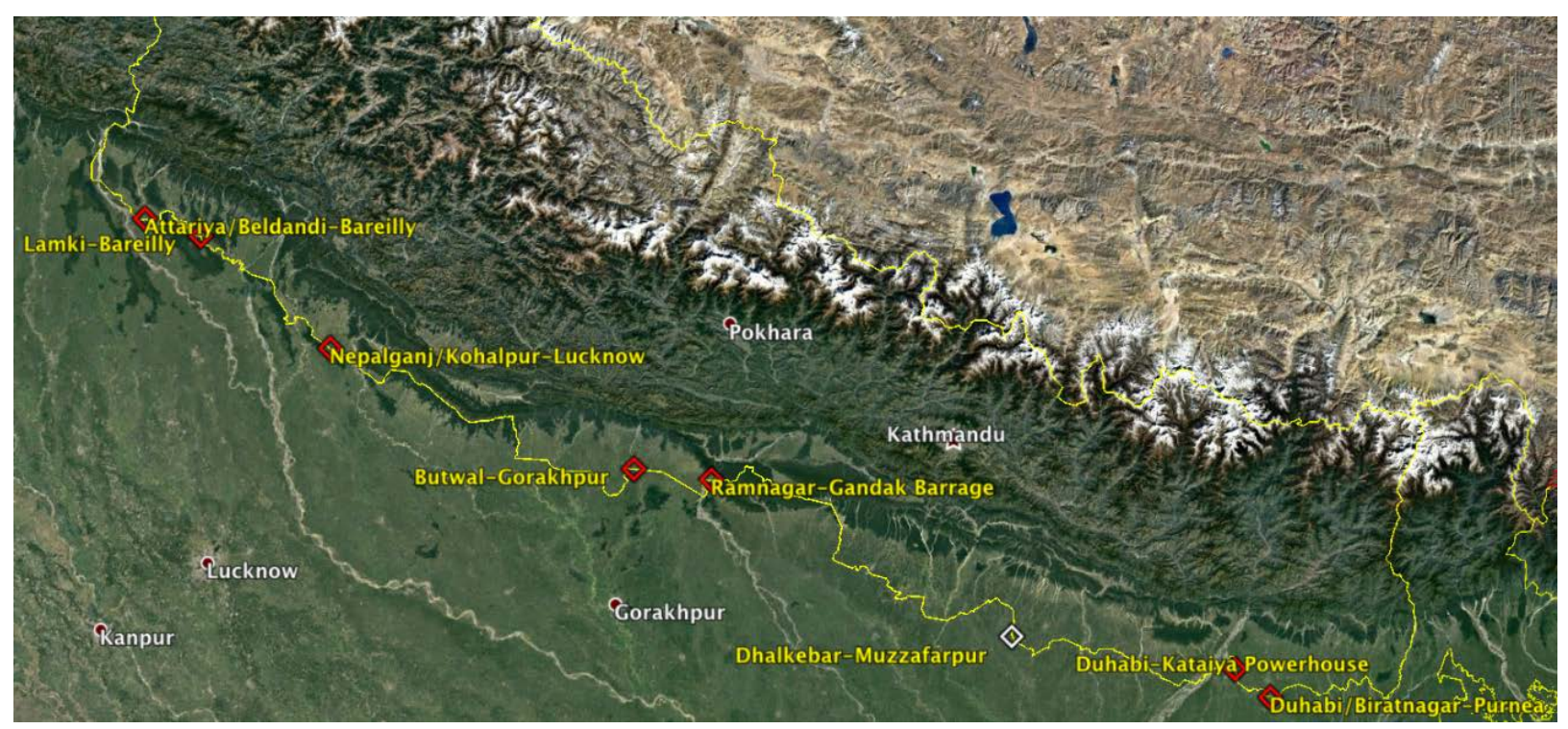

Figure 13. Map of major CBET interconnections.

Note: The Dhalkebar-Muzzafarpur connection would repower the existing line from $132 \mathrm{kV}$ to $400 \mathrm{kV}$, requiring no additional right-of-way.

\subsection{Terrain Assessment}

The U.S. Bureau of Land Management has a terrain classification system that it uses for permitting infrastructure development on land owned by the U.S. government. Each is a physical characteristic and is therefore comparable from one country to another. The categories are also identifiable by way of satellite imagery.

These different terrain types pose different challenges with respect to siting and building new transmission. In 2012, utilities and stakeholders in the western United States assigned cost multipliers to each category as part of a regional transmission planning exercise (Black \& Veatch 2012). Like Nepal, the western United States includes mountains, forests, hills, waterways, farmland, and urban areas. 
Table 7 shows the terrain categories and the multipliers associated with each terrain type. This analysis assumes that while the basic cost of building new transmission might differ between the United States and South Asia, stretches across forested areas and mountains will always be more difficult and more expensive than the basic cost of putting a line across flat farmland. The analysis makes the assumption that the degree of additional difficulty in the South Asian and U.S. contexts is comparable.

Table 7. Land Classification System

\begin{tabular}{cc}
\hline Terrain Type & Multiplier \\
\hline Scrubbed/Flat & 1.0 \\
\hline Farmland & 1.0 \\
\hline Desert/Barren Land & 1.05 \\
\hline Irrigated Farmlands/Wetlands & 1.2 \\
\hline Rolling Hills (2\%-8\% slope) & 1.4 \\
\hline Urban & 1.59 \\
\hline Mountains (>8\% slope) & 1.75 \\
\hline Forested & 2.25 \\
\hline
\end{tabular}

Source: Black \& Veatch 2012.

\subsection{Methodology and Results}

Figure 14 shows the types of terrain within a 40-kilometer radius of each CBET point. Irrigated farmland dominates all areas, although in Nepal some areas have forests and rolling hills close to the border.

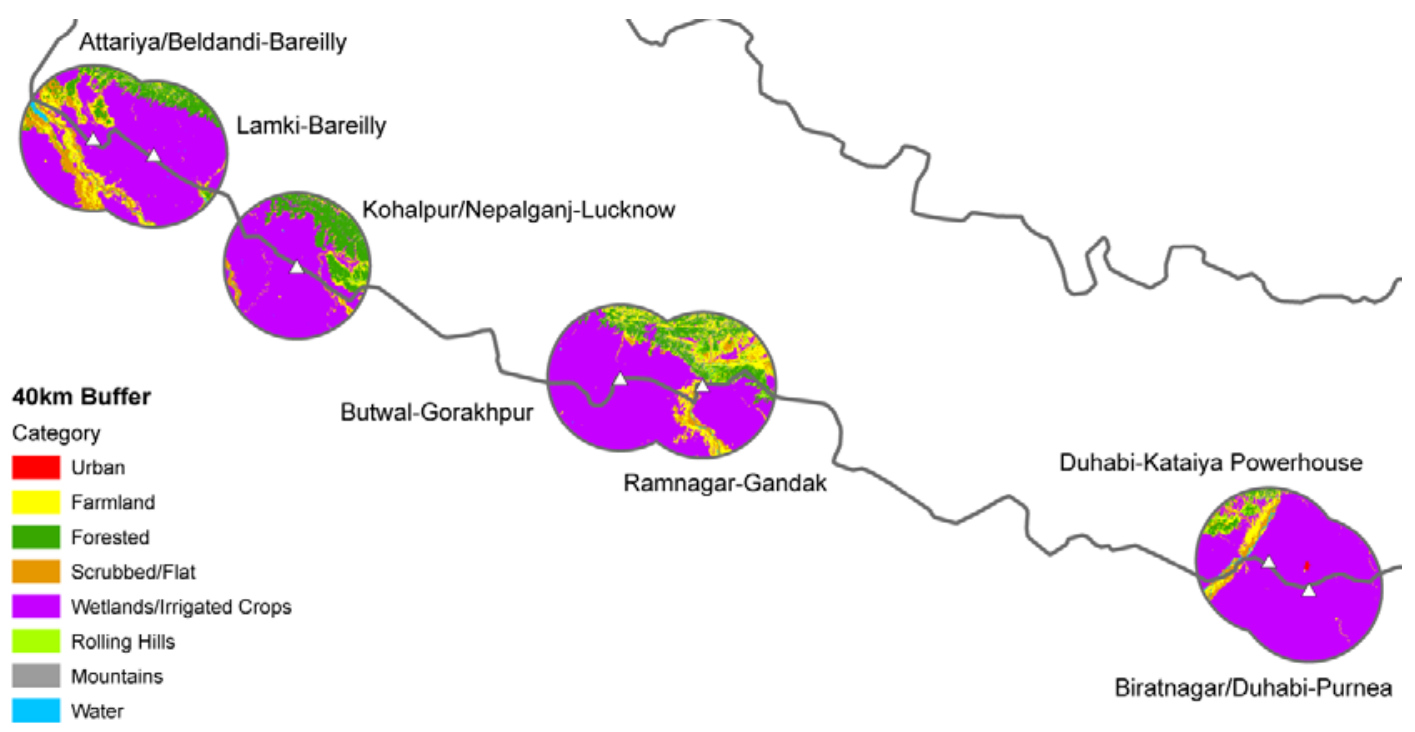

Figure 14. Geospatial analysis of areas around CBET points 
The last step of the analysis was to score each CBET point based on its weighted geospatial attributes as follows:

$$
\text { score }=\sum_{i} \text { share }_{i} * \text { multiplier }_{i}
$$

where $i$ is a terrain type, share $_{i}$ is the percentage of land within a 40-km radius of the CBET point characterized by that terrain type, and multiplier $i$ is the multiplier associated with the terrain type. A higher score indicates a higher proportion of difficult terrain in the vicinity of the CBET point. While it might be possible to find a low-cost transmission route in any of the areas, a higher score means relatively fewer options for doing so.

Table 8 shows results of the GIS screening and scoring. The scores suggest the largest number of options for minimizing the cost of building new transmission for CBET are likely to be found at the far eastern end of the Eastern Tarai (Biratnagar/Duhabi-Purnea and Duhabi-Kataiya Powerhouse) and at the far western end of the Western Tarai (Attariya/Beldandi-Bareilly).

Table 8. Scoring of CBET Points Based on Geospatial Attributes

\begin{tabular}{lcc}
\hline CBET Point & Score & Score Indexed to Mean \\
\hline Biratnagar/Duhabi-Purnea & 1.20 & 0.94 \\
\hline Duhabi-Kataiya Powerhouse & 1.22 & 0.96 \\
\hline Attariya/Beldandi-Bareilly & 1.24 & 0.97 \\
\hline Lamki-Bareilly & 1.28 & 1.00 \\
\hline Butwal-Gorakhpur & 1.28 & 1.00 \\
\hline Ramnagar-Gandak & 1.33 & 1.04 \\
\hline Kohalpur/Nepalganj-Lucknow & 1.39 & 1.09 \\
\hline
\end{tabular}

Note: lower score implies lower cost per mile.

All CBET points are surrounded by irrigated farmland, making the multiplier for that type of land the effective baseline for all scores. Kohalpur and Ramnagar are also close to forested hills, which could add to the cost of extending transmission from the border to Nepal's interior. 


\section{Production Cost Modeling}

Production cost modeling (PCM) provides a more detailed look into electricity supply and demand. For issues involving cross-border trading in South Asia, CBET can provide technical insights that a general economic analysis cannot. For example, hourly (and even subhourly) changes in supply and demand can cause prices to change throughout the course of a day. This affects the long-term value of flows across a particular transmission path.

One important question that PCM can test is the economic benefit of greater regional coordination. A typical simulation of the whole grid assumes that the flow of power across a political border is not constrained by institutional rules. Combining this basic scenario with a companion scenario that accounts for cross-border institutional factors can quantify the additional benefits of reforming CBET rules.

The most important limitation of PCM is that it does not account for generator fixed costs, which are outside the scope of PCM. PCM's objective is to operate a given set of units most efficiently, and it therefore considers only variable costs, not fixed.

PCM does not anticipate new investment decisions even if a new generator would significantly reduce the total variable cost of generation. It can, however, serve as a tool for evaluating a potential investment. By contrasting locational marginal price (LMP) in scenarios with and without the potential new investment, a developer or lender can test the likelihood that energy prices would be high enough to provide a return on investment if the new plant were built.

\subsection{Fundamentals}

PCM simulates how generators would be dispatched over a defined period of time if the sole objective were to minimize variable operating costs. This solution represents an economically ideal dispatch - what the system would tend to do absent any unpredictable shock or out-ofmarket intervention by authorities. Hours (or smaller time increments) are optimized sequentially, with the outcome of each time increment providing the initial conditions for optimizing the next time increment.

A simulation neither adds nor retires any generator, although it can leave an existing unit idle if using it would increase the cost of generation. Similarly, PCM accounts for transmission limits but does not add or expand transmission if a path is congested. It models all infrastructure as it is assumed to exist under the scenario being tested.

A PCM simulation relies on the operational specifications of all generators and transmission lines. These include:

- Each generator's cost of being turned on

- Minimum and maximum production limits (in megawatts) specific to each generator

- Maximum ramp rates (in megawatts per minute) specific to each generator

- Heat rates (in British thermal units of fuel per kilowatt-hour produced) specific to each generator 
- Limits on the amount of power that can flow safely across each transmission line.

The simulation also requires a number of assumptions, such as:

- Fuel prices

- Hourly demand for energy at specific points on the grid

- The amount of capacity to be held back as operating reserves

- Hourly generation profiles for wind and solar resources.

With all of these parameters, PCM identifies the generators capable of meeting demand for each hour (or each subhourly time increment) at the lowest total cost. It starts idle units for the next hour if the ones already committed do not have enough economical capacity left on them to meet the increase in load, or if transmission congestion limits the ability to ramp up the use of more economical resources.

An important output from PCM simulation is LMP. An LMP is the additional cost to the system if demand at a given point increases by $1 \mathrm{MW}$. If there is transmission congestion, the same operating time can have different LMPs at different points on the grid. Prices on the load side of a transmission constraint will tend to be higher than LMPs elsewhere on the system. This reflects the cost of shifting dispatch from low-cost units to higher-cost units on the load side of the constraint to avoid exceeding a transmission line's safe operating limit.

Day-ahead and real-time energy markets operated by regional transmission organizations in the United States rely on software similar to PCM to conduct security-constrained economic dispatch. There are two important differences between market dispatch software and PCM:

- Market dispatch software allows generators to submit strategically crafted offer curves (monotonically increasing price-to-quantity points for a single unit, with the ability to change the curves), whereas PCM usually relies on static assumptions about a unit's marginal cost, which is a function of the unit's heat rate and the price of fuel.

- Market dispatch software optimizes over a shorter time period (24 hours for day-ahead market operations), whereas PCM can optimize an entire year or longer.

In regional transmission organizations, load-serving entities pay the LMPs affecting their service areas, and generators receive payments based on the LMPs at the nodes where they connect.

\subsection{Questions To Be Addressed with PCM}

Prioritizing new CBET transmission will likely depend on how the addition of new generation in Nepal will affect optimal power flows on the grid regionally. The end of load shedding in Nepal will likely reverse the direction of some economic drivers for CBET. The full effect of this change on transmission investment, however, could depend on several other factors.

The second paper in this series (McBennett et al. 2019) uses PCM to test the key questions resulting from the economic analysis in this report. The scenarios examine different levels of new IPP capacity additions, the effect of cross-border operational coordination on potential CBET benefits, the potential impacts of greater CBET between India and Nepal on India's 
ability to integrate large penetrations of new wind and solar capacity, and the effects a dedicated Nepal-Bangladesh trade would have on CBET value. 


\section{References}

Black \& Veatch. 2012. Capital Costs for Transmission and Substations: Recommendations for WECC Transmission Expansion Planning (report prepared for the Western Electricity Coordinating Council). Overland Park, KS: Black \& Veatch. https://www.wecc.biz/Reliability/1210 BV WECC TransCostReport Final.pdf.

CAISO (California Independent System Operator). 2018. Western EIM Benefits Report: Fourth Quarter 2017. Folsom, CA: CAISO. https://www.westerneim.com/Documents/ISOEIMBenefitsReportQ4 2017.pdf.

CEA (Central Electricity Authority). 2016a. Review of Performance of Hydro Power Stations, 2015-16. New Delhi, India: CEA.

CEA. 2016b. Overview of Annual Performance Review of Thermal Power Stations for 2014-15.

FERC (Federal Energy Regulatory Commission). 2011. "Transmission Planning and Cost Allocation by Transmission Owning and Operating Public Utilities (Final Rule). Docket No. RM10-23-000 (Order 1000).” https://ferc.gov/industries/electric/indus-act/trans-plan.asp.

GoI/GoN (Government of India and Government of Nepal). 2017. India-Nepal Joint Statement during the State Visit of Prime Minister of Nepal to India. August 23-27, 2017.

IBN (Office of the Investment Board of Nepal). 2017. "Our Projects.” http://ibn.gov.np/ourprojects. Accessed January 2018.

IEX (Indian Energy Exchange). 2017. Day-ahead market prices for zones E1 (including Bihar) and N2 (including Uttar Pradesh). New Delhi, India: IEX.

London Economics. 2013. Estimating the Value of Lost Load (briefing paper prepared for the Electric Reliability Council of Texas, Inc.). Boston: London Economics. http://www.ercot.com/content/gridinfo/resource/2014/mktanalysis/ERCOT ValueofLostLoad Li teratureReviewandMacroeconomic.pdf.

McBennett, B., A. Rose, D. Hurlbut, D. Palchak, and J. Cochran. 2018. Cross-Border Energy Trade between Nepal and India: Assessment of Trading Opportunities. Golden, CO: National Renewable Energy Laboratory technical report (forthcoming).

MCC (Millennium Challenge Corporation). 2017. Summary of the Nepal Compact. Washington, DC: MCC.

NEA (Nepal Electricity Authority). 2014. "Energy Demand and Peak Load Forecasts (Base Case)." Email correspondence with NEA planning department (on file with NREL).

NEA. 2017a. Annual Report. Kathmandu, Nepal: NEA.

NEA. 2017b. Daily operation logs, Nepalese calendar year 2073.

NEA. 2017c. IPP list. Updated spreadsheet, NEA Power Trade Department. 
NEA. 2017d. NEA Board Decisions on the Power Purchase Rates and Associated Rules for PPA of ROR/PROR/Storage Projects Effective from 2074/01/14. April 27, 2017.

NEA. 2018. Annual Report. Kathmandu, Nepal: NEA.

POSOCO (Power System Operation Corporation Ltd.). 2016. "Electricity Demand Pattern Analysis" (volumes for Bihar, Damodar Valley Corporation, Delhi, Jharkhand, Odisha, Rajasthan, Sikkim, Uttar Pradesh, Uttarakhand, and West Bengal).

https://posoco.in/reports/electricity-demand-pattern-analysis/.

POSOCO. 2017a. Annual Report, Eastern Regional Load Despatch Centre. New Delhi, India: POSOCO.

POSOCO. 2017b. Annual Report, Northern Regional Load Despatch Centre.

SARI/EI and IRADe (South Asian Regional Initiative for Energy Integration and Integrated Research and Action for Development). 2017. "Economic Benefits from Nepal-India Electricity Trade."

Subedi, B. 2017. "Financial closure deadline likely to be extended again." Kathmandu Post. September 16, 2017.

The Independent. 2017. "Power Development Board to sign hydropower import deal with Nepal." July 10, 2017. http://www.theindependentbd.com/home/printnews/103379.

WECS (Water and Energy Commission Secretariat). 2017. Electricity Demand Forecast Report (2015-2040). Kathmandu, Nepal: WECS, Government of Nepal.

World Bank. 2017. "GDP Per Capita (Current US\$).”

https://data.worldbank.org/indicator/NY.GDP.PCAP.CD. 


\section{Appendix: Exchange Rates Applied to the Analysis \\ Indian rupees to U.S. dollar \\ Nepalese rupees to U.S. dollar \\ 64.50 \\ 102.75}

